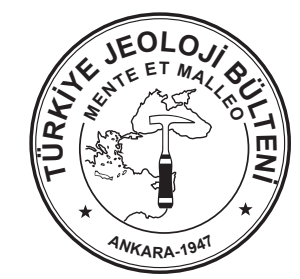

\title{
Kemalpaşa (İzmir) Pliyo-Kuvaterner Havzasının Stratigrafik Evrimi
}

\author{
Stratigraphic evolution of the Kemalpaşa (İzmir) Plio-Quaternary Basin \\ Fikret GÖKTAŞ', H. Yavuz HAKYEMEZ ${ }^{2}$ \\ ${ }^{1 .}$ MTA Genel Müdürlüğü, Ege Bölge Müdürlüğ̈̈, 35040 İmir \\ (e-posta: fikretgoktas50@gmail.com) \\ 2. MTA Genel Müdürlüğü, Dumlupınar Bulvarı 139, 06800 Ankara
}

\section{ÖZ}

Batı Anadolu'da, kısa süreli bir sıkışma fazını izleyerek yaklaşık 5 my önce yeniden etkinleşen ve D-B uzanımlı grabenlerin açılımını sağlayan K-G genişleme sürecinde Kemalpaşa Pliyo-Kuvaterner havzası oluşmuştur. Gediz Grabeni'nin batıya çatallanan kolunu oluşturan havzanın Neojen temelini, bölgesel ölçekte açılı uyumsuzlukla birbirinden ayrılan Alt-Orta Miyosen ve Üst Miyosen-en Alt Pliyosen karasal tortul istifleri oluşturur. Alt-Orta Miyosen dolgularını kapsayan Kemalpaşa grubu, yelpaze deltası ortamında çökelmiş Dereköy, gölsel Örnekköy, flüviyal Topçutepe formasyonları ve kalkalkali andezitik Yukarıkızılca volkaniti ile simgelenir. Geç Miyosen-erken Erken Pliyosen tortullaşmasını yansıtan Çiçekliköy grubu ise, altta alüviyal Ulucak formasyonu ile üstte yer alan gölsel Yaka kireçtaşından oluşur.

Kemalpaşa havzasının birbirini izleyen iki evreli dolgulanma süreci, geç Erken Pliyosen-Pleyistosen ve Holosen istiflerine ayrılan Gediz grubu ile temsil edilir. Gediz Grabeni ana sıyrılma fayının tavan bloğu üzerinde geç Erken Pliyosen-Pleyistosen döneminde çökelen birinci evre istifi, egemen gölsel Çiniliköy alüviyal Kızllca ve Armutlu formasyonlarından oluşur. Yüksek aç11ı Kemalpaşa verev-normal fay1 tarafından birinci evre dolguları üzerinde bakışımsız açılan Holosen havzasında, ikinci evreyi simgeleyen alüvyon yelpazesi ve akarsu çökelleri dolgulanmaktadır.

Anahtar Kelimeler: Kemalpaşa havzası, Gediz Grabeni, Pliyo-Kuvaterner, havza evrimi

\section{ABSTRACT}

The Kemalpaşa Plio-Quaternary basin was constructed during the period of N-S extension which has been reactivated nearly $5 \mathrm{Ma} B P$ causing the opening of $E$-W trending grabens following a short-time compression phase in Western Anatolia. The Kemalpaşa basin, southwestern one of the westerly furcated branches of Gediz Graben, has a Neogene basement composed of Lower-Middle Miocene and Upper Miocene-lowermost Pliocene continental sedimentary sequences seperated by a regional unconformity. The Lower-Middle Miocene Kemalpaşa group is represented by the Dereköy, Örnekköy and Topçutepe formations deposited in fandelta, lacustrine and fluvial environments respectively and the calcalkaline andesitic Yukarlkızlca volcanics. The Çiçekliköy group, which is deposited during the Late Miocene to early Early Pliocene, 
consists of alluvial Ulucak formation in its lower part and overlying lacustrine Yaka limestone.

The deposition in the Kemalpaşa basin, which is formed in two successive phases during the late Early Pliocene and Holocene respectively, is represented by the Gediz group. The first phase depositsof late Early Pliocene-Plesitocene on the hanging wall of Gediz Graben detachment fault arethe lacustrine Çiniliköy formation and lateral alluvial Klzllca and Armutlu formations. Alluvial fan and fluvial deposits of the second phase have been deposited in the Holosen basin opening on the first phase deposits by the Kemalpaşa high-angled oblique-slip normal fault.

Key words: Kemalpaşa basin, Gediz Graben, Plio-Quaternary, basin evolution

\section{GİRIŞ}

Bu çalışma, Gediz Grabeni'nin batı kolunu oluşturan Kemalpaşa alt havzasında, geç Erken Pliyosen'de başlayan ve günümüzde devam eden karasal tortullaşmanın stratigrafisine yöneliktir. Arazi çalışmaları havzanın batı kesiminde yürütülmüştür (Şekil 1 ve 2). Kemalpaşa Havzası'nı da içine alan genel jeoloji amaçlı ilk çalışmada (Akdeniz vd., 1986), Orta Miyosen-Pleyistosen aralığında dolgulanmış çökel istifler ayrılmamış ve "Vişneli formasyonu" kapsamında haritalanmıştır (Şekil 3). Paton (1992), Turgutlu güneyindeki iki aktif normal fay seti arasında sınırlanan olası Pliyo-Kuvaterner yaşı limnikflüviyal kırıntılıları "Turgutlu formasyonu" adıyla ayırtlamış; Gediz Grabeni sırılma fayı (GGSF) ile Kemalpaşa fayı (Emre ve Barka, 2000; Emre vd., 2005; Sözbilir vd., 2011) arasında yüzeyleyen havza dolgularını ise Neojen çökelleri olarak yorumlamıştır. Gediz havzasının B (Kemalpaşa) ve KB (ManisaSaruhanlı) bölümlerindeki çalışmalarda (Hakyemez vd., 1999, 2013; Sözbilir vd., 2011; Özkaymak vd., 2012) Pliyo-Kuvaterner stratigrafisi yeterince araştırılmamıştır (Şekil 3). Bu çalışmanın temelini oluşturan Göktaş (2012), Kemalpaşa havzasının Kuvaterner dolgusu ile Neojen temeline yönelik ilk ayrıntılı çalışmayı yapmıştır.

\section{KEMALPAŞA HAVZASININ TEMEL KAYALARI}

Geç Erken Pliyosen'de biçimlendiği öngörülen Kemalpaşa havzasının bakışımsız gelişimi ve Pleyistosen boyunca tektonik denetimli çökelimi GGSF tarafından belirlenmiştir. Havzanın geç
Erken Pliyosen-Pleyistosen yaşlı dolgusu, kuzey ve güneybatıdan Üst Kretase-Paleosen yaşlı Bornova fliş zonu (Okay ve Siyako, 1991) ile Üst Miyosenen Alt Pliyosen çökelleri (Çiçekliköy gubu) tarafindan sınırlanır. Güney-güneydoğuda, Kocaçay havzasının Alt-Orta Miyosen yaşlı yelpaze deltası çökelleri (Dereköy formasyonu: Sözbilir vd., 2011), Menderes Masifi, Kikladik Kompleks (Candan vd., 2011) ve Likya Napları kapsamında değerlendirilen Bodrum Napı'na (Konak ve Çakmakoğlu, 2007) ait kaya birimleri yer alır (Şekil 2).

Erken-Orta Miyosen yaşlı Kemalpaşa grubu (Sözbilir vd., 2011; Göktaş, 2012) ile Geç Miyosenerken Erken Pliyosen yaşlı Çiçekliköy grubu, havza tabanında bulunan Neojen kaya birimlerini kapsar. Sözbilir vd. (2011)'nin tanımladığı Kocaçay havza dolgusunun çalışma alanındaki uzantılarından oluşan Kemalpaşa grubu, alttan üste, kızıl-bordo renkli yelpaze deltası çökellerinden yapılı Dereköy, gölsel Örnekköy, flüviyal Topçutepe formasyonları ve kalkalkali andezitik Yukarıkzılca volkaniti ile simgelenir. Kemalpaşa grubu kaya birimleri üzerinde açılı uyumsuzlukla yer alan Çiçekliköy grubu, altta alüviyal Ulucak formasyonu ve geçiş ilişkisiyle üstte yer alan gölsel Yaka kireçtaşından oluşur (Şekil 4).

\section{Dereköy Formasyonu}

Kızıl-bordo renkli birim, çakıltaşı arakatkılı kumtaşı egemen istifiyle simgelenir ve seyrek olarak kireçtaşı-çamurtaşı aradüzeyleri kapsar (Şekil 5). 


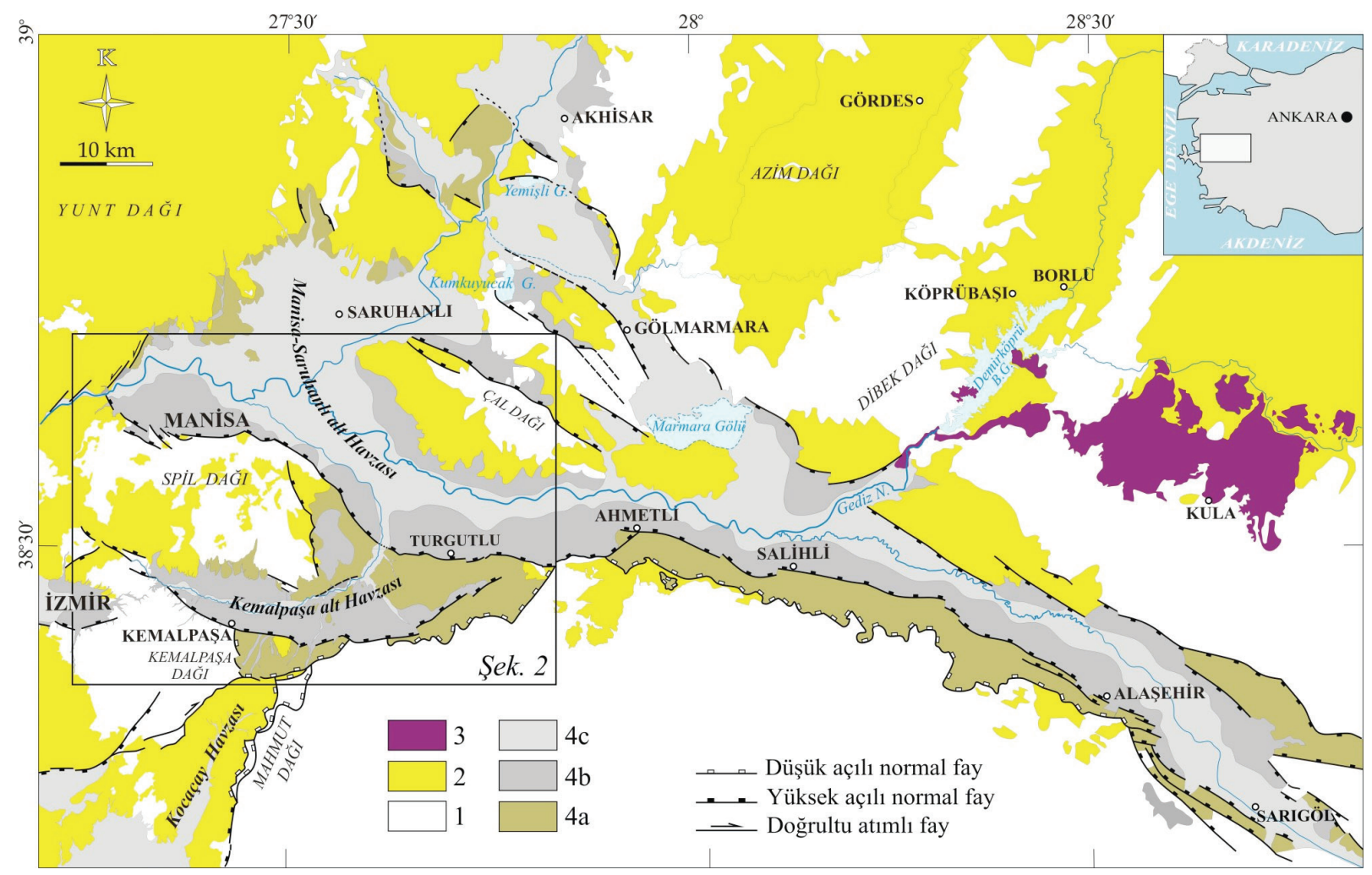

Şekil 1. İnceleme alanının Gediz havzası içindeki konumu: 1. Neojen öncesi temel kayaları, 2. Neojen çökelleri vevolkanitleri, 3. Kula volkanitleri (Kuvaterner), 4. Gediz grubu (a: geç Erken Pliyosen-Pleyistosen yaşlı çökeller, b: Alüvyon yelpazesi çökelleri [Holosen], c: Akarsu çökelleri [Holosen]).

Figure 1. Location of the study area in the Gediz basin: 1. Pre-Neogene basement rocks, 2. Neogene sediments and volcanics, 3. Kula volcanics (Quaternary), 4. Gediz group (a: latest Early Pliocene-Pleistocene deposits, b: Alluvial fan deposits [Holocene], c: Fluvial deposits [Holocene]).

Havzanın batı kesimlerinde yüzeyleyen tortul istif içinde, Bornova flişi kapsamındaki Mesozoyik yaşli allokton karbonat kayalarından aktarılmış mega bloklar bulunur. Az çok yanal sürekli ve düzlemsel paralel konumlu kumtaşı katmanlarının alt ve üst sınırları çoğu yerde belirgin ve düzgündür. Tane destekli ve yüksek dokusal olgunluktaki kumtaşları, karbonatla çimentolanmış ve iyi pekişmiştir. Tekli ve çoklu aradüzeyler olarak kumtaşı egemen istifi içinde yer alan çakıltaşlarında ortalama çakıl boyutları, ufak çakıl ile iri çakıl büyüklük sınırları arasında değişir. Doku, kaba kumtaşından oluşan ara gereç destekli ya da tane destekli-ara gereç dolguludur. İstif içinde seyrek olarak mikritik ya da algli kireçtaş1 aradüzeyleri bulunur. Düzgün inceorta katmanlı ve açık sarı-gri ayrışma renkli mikritik kireçtaşı düzeyleri, yersel olarak linyitli çamurtaşı arakatmanları kapsar. Çamurtaşı litofasiyesi, tortul istifin genellikle kumtaşı egemen bölümleri içinde metrik kalınlıklarda tortullaşma üniteleri olarak bulunur ya da kireçtaşı aradüzeylerinin taban kesitlerinde kiltaşları ile birlikte yer alır.

KKD gidişli Kocaçay havzasında dolgulanan kırıntılı istif, gölsel yelpaze deltas1 çökelimini yansıtır (Sözbilir vd., 2011; Göktaş, 2012). Başlıca kayatürü bileşenleri, havzanın bat1 kenarında Bornova filişi, doğu kenarında ise baskın olarak Bodrum Napı'ndan türemiştir. Geçici göl çökelimini yansıtan kireçtaşı aradüzeylerinin çoğunlukla taban kesimlerinde, yüksek organik gereç içeren çamurtaşları ve linyit oluşumuyla belgelenen yerel bataklıklar gelişmiştir. 


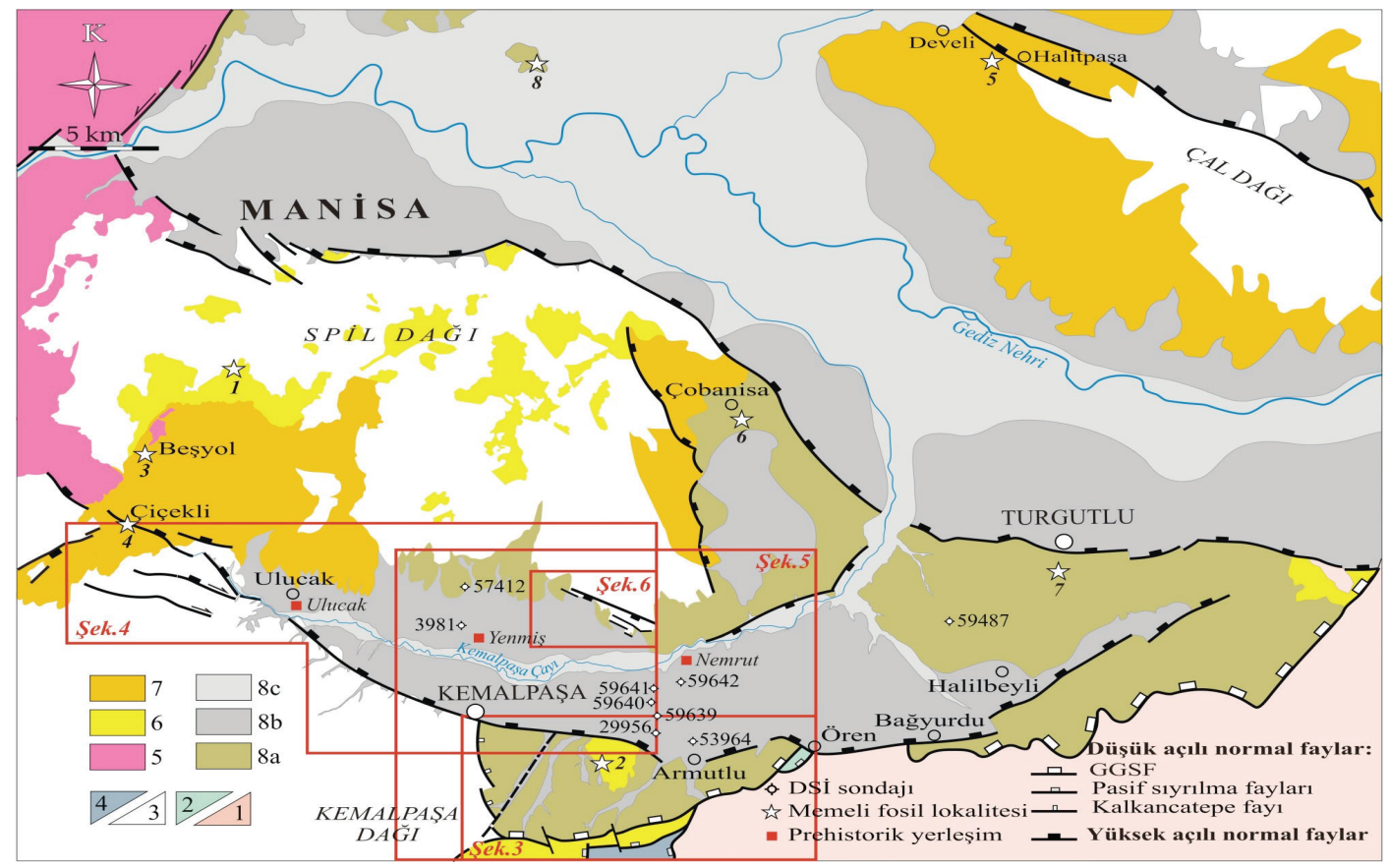

Şekil 2. Kemalpaşa havzasının Güncel sınırları ve yüzeyleyen stratigrafi birimleri: 1. Menderes Masifi, 2. Kikladik Kompleks, 3. Bornova Fliş Zonu, 4. Bodrum Nap1, 5. Neojen volkanitleri, 6. Erken-Orta Miyosen yaşlı çökeller, 7. Geç Miyosen-erken Erken Pliyosen yaşlı çökeller, 8. Gediz grubu (a: Geç erken PliyosenPleyistosen yaşlı çökeller, b: Alüvyon yelpazesi çökelleri [Holosen], c: Akarsu çökelleri [Holosen]). Memeli fosil lokaliteleri: 1: Sabuncubeli, 2: Yukarıkızılca, 3: Beşyol, 4: Çiçekliköy, 5: Develi-Halitpaşa, 6: Çobanisa, 7: Turgutlu çöplüğü, 8: Kızılgeri.

Figure 2. Present borders of Kemalpaşa basin and exposed stratigraphic units: 1. Menderes Massif, 2. Cycladic Complex, 3. Bornova Flysch Zone, 4. Bodrum Nappe, 5. Neogene volcanics, 6. Early-Middle Miocene deposits, 7. Late Miocene-earliest Early Pliocene deposits, 8. Gediz group (a: Latest Early PliocenePleistocene deposits, b) Alluvial fan deposits [Holocene], c) Fluvial deposits [Holocene]). Mammalian fossil localities: 1. Sabuncubeli, 2. Yukarıkızlca, 3. Beşyol, 4. Çiçekliköy, 5. Develi-Halitpaşa, 6. Çobanisa, 7. Turgutlu dumping ground, 8. Kuzllgeri.

Menderes Masifi ve tektonik örtüsünü oluşturan Bodrum Napı kayalaryyla ilksel dokanak ilişkisinin, KKD uzanımıyla Kocaçay havzasının oluşumu ve dolgulanmasını denetleyen Mahmutdağı fayı ile doğu devamındaki düşük açılı verev/normal fay sistemi (GGSF) tarafindan sinsedimanter olarak belirlendiği ileri sürülmektedir(Sözbilirvd., 2011). Bu model, K-G genişleme sürecinde Kocaçay havzası ile Gediz Grabeni'nin birlikte açıldığı ve dolgulanmanın Erken Miyosen'de başladığı öngörüsüne dayanır. Kocaçay havzası ile Gediz grabenleşmesi arasındaki yapısal ilişkinin kinematiğini tartışmak bu çalışmanın konusu olmamakla birlikte, bu makalede, masifin yükselimi sürecinde Dereköy formasyonunun üzerinde çökeldiği allokton kütlelerle birlikte postsedimanter (pasif) olarak siyrılmaya devam ettiği ve yer değiştirerek paraotokton konum kazandığ kabul edilmiştir. Kocaçay havzasını batıdan sınırlayan Bornova fliş zonu kayalarıyla dokanak, Kesmedağı fayı tarafından belirlenir (Sözbilir vd., 2011; Göktaş, 2012). Genelleştirilmiş stratigrafide uyumsuzlukla üste geldiği kabul edilen Örnekköy formasyonu ile dokanak ilişkisi gözlenmez. Kemalpaşa Havzası'nın birinci evre oluşumunu ve dolgulanmasını denetleyen GGSF ve Kurudere köyünden itibaren Kemalpaşa ilçe merkezine doğru uzanan düşük açılı normal fay sistemi (Kalkancatepe fayı: Sözbilir vd., 2011), geç Erken Pliyosen-Pleyistosen yaşlı birimler ile Dereköy formasyonu arasında sınır oluşturur (Şekil 5). 


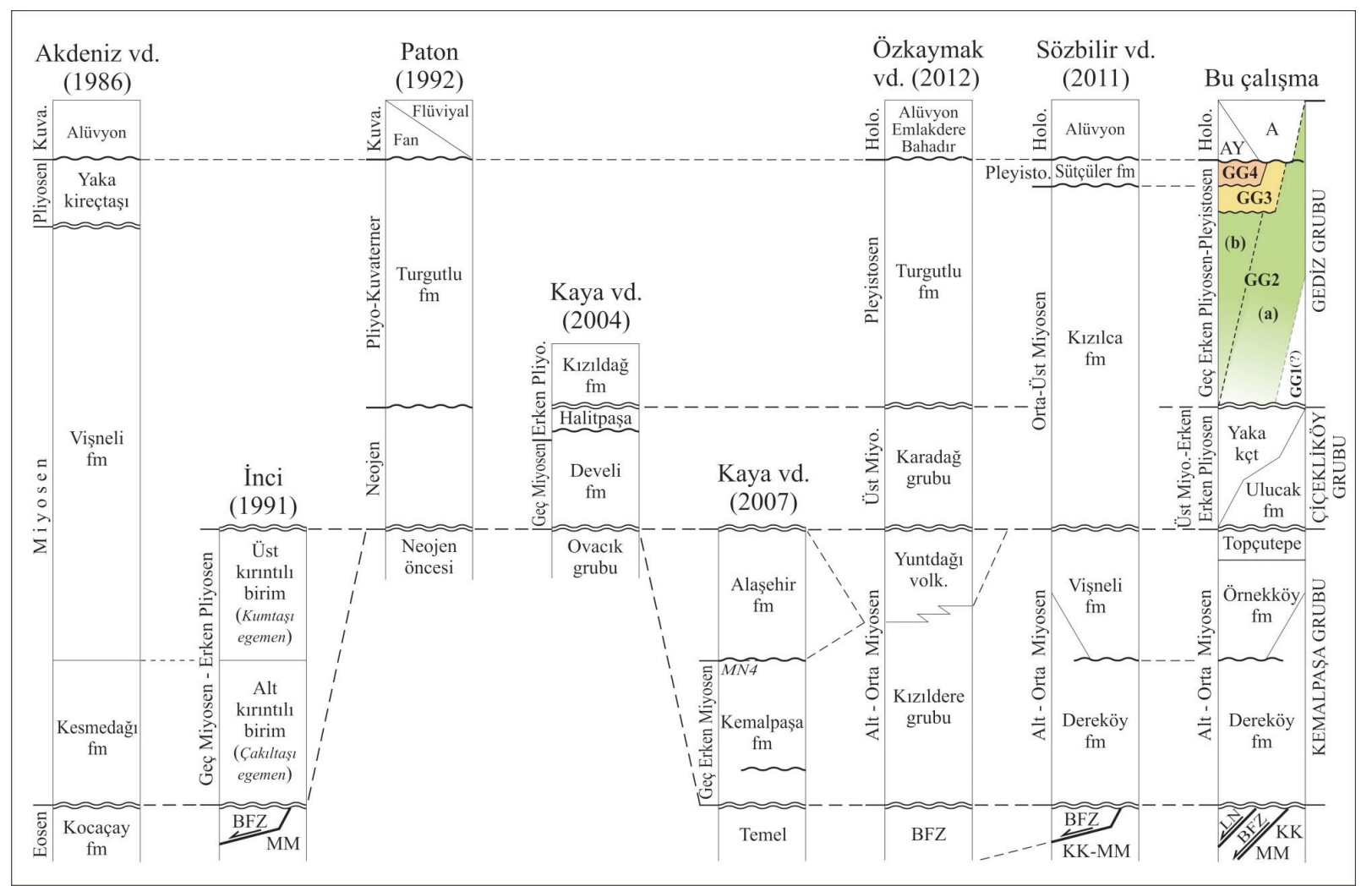

Şekil 3. Kemalpaşa havza dolgusu ve temel kayalarına yönelik önceki stratigrafik önermelerin, bu çalışmanın sonuçlarıyla karşılaştırılması. AY: Alüvyon yelpazesi çökelleri, A: Akarsu çökelleri, GG: Gediz Grubu, BFZ: Bornova Fliş Zonu, KK: Kikladik Kompleks, MM: Menderes Masifi.

Figure 3. Correlation of previous stratigraphies proposed for the Kemalpaşa basin fill and its basement rocks with the results of this study. AY: Alluvial fan deposits, A: Fluvial deposits, GG: Gediz Group, BFZ: Bornova Flysch Zone, KK: Cycladic Complex, MM: Menderes Massif.

İzmir-Manisa karayolu üzerindeki Sabuncubeli Mevkii çevresinde (Şekil 2) yüzeyleyen ve Dereköy formasyonu istifinin alt bölümüne eşdeğer olan yelpaze deltası çökellerinde, MN3 biyozonuna (18-20,5 my aras1: Steininger, 1999) ait küçük memeli fosillerinin tanımlandığı bilinmektedir (Bruijn vd., 2006; Kaya vd., 2007; Mayda, 2008). Kocaçay havzasında, istifin üst kesimlerindeki masif çamurtaşları içinde Kaya vd. (2007) tarafindan tanımlanan küçük memeli faunası da MN4 biyozonu (17-18 my aras1: Steininger, 1999) kapsaminda değerlendirilmiştir. Esas olarak geç Erken Miyosen döneminde geliştiği anlaşılan Dereköy formasyonu tortullaşmasının Orta Miyosen'de devam ettiği kabul edilmektedir (Sözbilir vd., 2011).

\section{Yukarıkızılca Volkaniti}

Yukarıkızılca volkaniti (Göktaş, 2012; 2015), Dereköy formasyonunun yelpaze deltası çökelleri arasına yerleşmiştir (Şekil 5). Yukarıkızılca köyünün yaklaşık 2,5 km GB'sinde ayırtlanan mavimsi gri renkli lav kütlesi, GGSF'nin verevnormal faylarla ötelenmiş taban bloğunda yüzeyler. Ana element bileşimine göre kalkalkali andezit olarak tanımlanan porfirik dokulu lavların fenokristal kapsamı, plajiyoklaz, amfibol, biyotit, piroksen ve kuvarstan oluşur. Yukarıkızılca volkanitinden $15,6 \pm 0,6$ my K/Ar yaşı alınmıştır (Göktaş, 2012; 2015). 


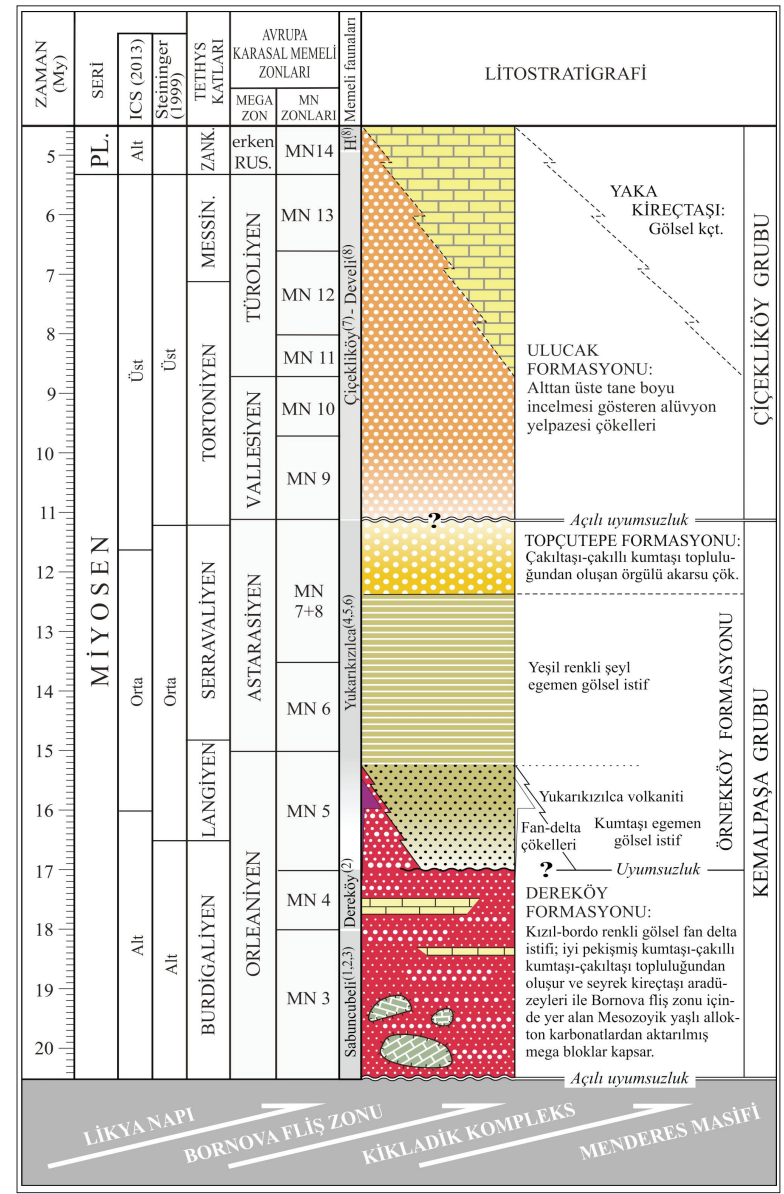

Şekil 4.Kemalpaşa havzasının temelini oluşturan Neojen yaşlı kaya birimlerinin genelleştirilmiş stratigrafisi (Göktaş, 2012'den değişiklikle). H.: Halitpaşa memeli faunası. Memeli faunası referansları: ${ }^{(1)}$ Bruijn vd. (2006), ${ }^{(2)}$ Kaya vd. (2007), ${ }^{(3)}$ Mayda (2008), ${ }^{(4)}$ Becker-Platen vd. (1975b), ${ }^{(5)}$ Saraç (2003), ${ }^{(6)}$ Rummel (1998), ${ }^{(7)}$ Kaya (1994), ${ }^{(8)}$ Kaya (2004).

Figure 4. Generalized stratigraphic section of the Neogene basement rocks of the Kemalpaşa basin (modified after Göktaş, 2012). H.: Halitpaşa mammalian fauna. Reference for mammalian faunas: (1) Bruijn vd. (2006), (2) Kaya vd. (2007), (3) Mayda (2008), ${ }^{(4)}$ Becker-Platen vd. (1975b), "(5)Saraç (2003), (6) Rummel (1998), (7)Kaya (1994), ${ }^{(8)}$ Kaya (2004)

\section{Örnekköy Formasyonu}

Örnekköy formasyonu (Göktaş, 2012), ağırlıklı olarak yeşil kiltaşından oluşan bir istifle simgelenir (Şekil 5). Kumtaşı ve çamurtaşı aradüzeyleri kapsayan masif kiltaş1 egemen istifin alt bölümlerinde, çakıltaş1çakıllı kumtaşı-kumtaşı topluluğu yer alır. Seyrek olarak gözlenen yuvarlak küçük çakıllardan yapılı çakıltaşları iyi pekişmiştir ve kalınlıkları bir metreye kadar çıkar. Biyoturbasyon nedeniyle bütünüyle masif görünen ince-orta taneli kumtaşı egemen bölümlerde, beyaz renkli ve ince kavk1lı gastropodlara rastlanır. Kireçtaşı ve beyaz renkli dolomit arakatmanları, kiltaşı istifi içinde az oranda bulunur. Kum boyu ekstraklastlar ve seyrek gastropodlar kapsayan kireçtaşı düzeylerinin istif içindeki bağıl konumları belirgin değildir. Yersel olarak gözlenen düzlemsel paralel laminalı kiltaşı düzeyleri desimetrik kalınlıklardadır ve mikritik kireçtaşı katmanlarıyla birlikte bulunur. Becker-Platen vd. (1975b), 'kalsifiye tüfit' katmanlarının varlığına değinmiştir. Desimetrik kalınlıklarda seyrek aradüzeyler olarak bulunan kaba taneli kumtaşı ve çakılcıktaşı, masif ya da düzlemsel paralel katmanlıdır.

Tortul istifin önemli bölümünü oluşturan masif kiltaşları kalıcı göl ortamının ürünüdür. Gölsel istif içinde Becker-Platen vd. (1975b) tarafından varlığına değinilen tüfit katmanları, Kocaçay havzasında Aşağıvişneli üyesi (Göktaş, 2012) içinde ayırtlanan ve Göktaş (2013)'ta Cumaovası riyolitik volkanizmasıyla ilişkilendirilen $13.8 \pm 0.1$ My $\mathrm{Ar}^{40} / \mathrm{Ar}^{39}$ yaşlı (Sözbilir vd., 2011) felsik kül döküntülerinin korelanı olmalıdır. Karbonat çimentolu çakıltaşı ve kumtaşı katmanları, çökelimi Orta Miyosen'de devam eden Dereköy formasyonunun sualtı yanal uzantıları olabilir.

Çalışma alanında tabanı yüzeylemeyen istifin, Dereköy formasyonu üzerinde uyumsuzlukla yer aldığı kabul edilmiştir (Şekil 4). Dereköy formasyonuyla birlikte GGSF'nin tavan bloğunu oluşturan ve bu konumuyla havzanın tabanındayer alan birim, Kemalpaşa normal fayının işlemesiyle taban blokta yüzeylemiştir (Şekil 5). Topçutepe formasyonu tortul istifi üzerler. Gediz grubunun geç Erken Pliyosen-Pleyistosen istifinde yer alan Kızılca formasyonunun izole kalıntıları, uyumsuz dokanaklarla birimin üzerinde yer alır.

Becker-Platen vd. (1975b) tarafindan tanımlanan ve Saraç (2003) tarafından kapsamı genişletilen "Yukarıkızılca memeli faunası" 


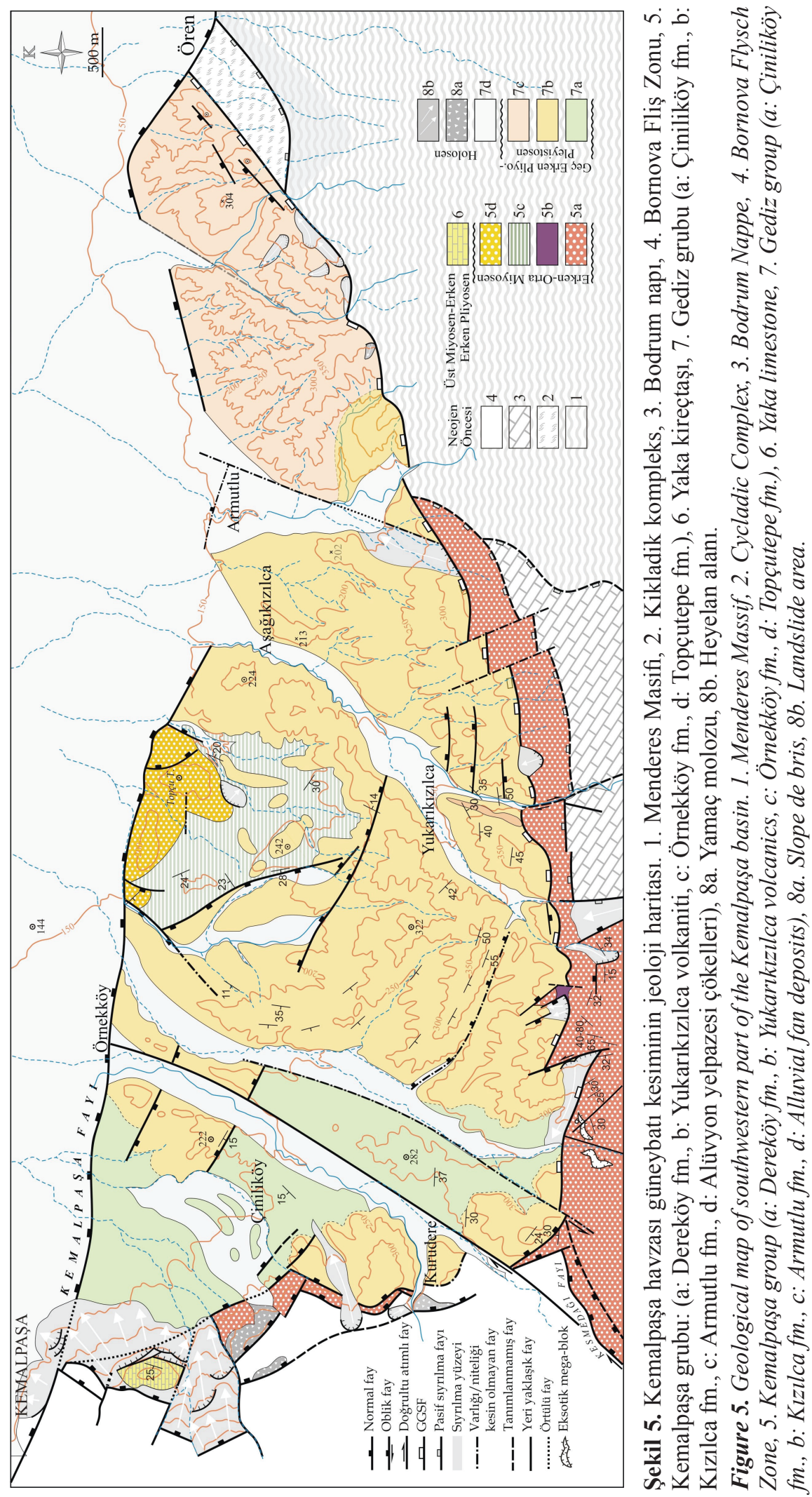


(Erinaceus sp.,Prolagus oeningensis, Alloptox sp., Cricetodon (Palaeocricetus) cf. caucasicus., Democricetodon sp., Megacricetodon cf. similis, Peridyromys dehmi, Spermophilinus sp., Gliridae sp. indet., Suidae sp. indet, Cervidae sp. indet.), Mayda (2014)'ya göre MN5'ten çok MN6 biyozonu üyelerini kapsar ve "Çandır fauna grubu" (Becker-Platen vd.,1975a) ile korele edilebilir. Rummel (1998)'in tanımladığı Cricetidae faunası (Byzantinia $\mathrm{cf}$. $c a-$ riensis, Democricetodon aff. freisingensis, Megacricetodon similis) ise $\mathrm{MN} 7+8$ biyozonuna aittir. Küçük memeli topluluğunun geç Orleaniyen-Astarasiyen megazonlanı arasındaki dağılımına dayanılarak, tortullaşmanın geniş anlamda Orta Miyosen döneminde geliştiği kabul edilmiştir (Şekil 4).

Örnekköy formasyonu, Sözbilir vd. (2011) tarafından Kocaçay havzasında tanımlanan "Vişneli formasyonu" kapsamındaki gölsel çökellerin yanal uzantısıdır. İstifin yeşil kiltaşı egemen bölümleri, "Aşağıvişneli üyesi” (Göktaş, 2012) ile deneştirilebilir.

\section{Topçutepe Formasyonu}

Topçutepe formasyonu, çakıltaşı-çakı1lı kumtaşı ile simgelenen kırıntılı çökellerden oluşur (Şekil 4 ve 5). Tortul istifin çoğunlukla zayıf pekişmiş olması ve sarımsı gri ayrışma rengi tipiktir. Genellikle iyi yuvarlanmış ufak-iri çakıllardan yapılı çakıltaşları ve kumtaşları tortul istife egemendir. Çakıltaşları, kaba taneli kumdan oluşan ara gereç desteklidir. Çapraz katmanlanmanın ender olarak gözlendiği çakılcıklı ve ufak çakı1lı kaba kumtaşları, çakıltaşlarıyla birlikte bulunur.

Topçutepe istifi Örnekköy formasyonunu uyumlu(?) olarak üstler; ancak dokanaklar çok açık değildir. Holosen havza oluşumunu belirleyen Kemalpaşa fayı, taban blokta yüzeyleyen Topçutepe formasyonu ile tavan blokta çökelmekte olan Holosen alüvyon yelpazeleri arasında sınır oluşturur. Birimin üst dokanağı Holosen aşınımıyla belirlenmiştir. Topçutepe formasyonu ile -bölgenin Neojen stratigrafisinde açılı uyumsuzlukla üste geldiği öngörülen- Geç Miyosen-erken Erken Pliyosen yaşlı Çiçekliköy grubu çökellerinin dokanağı bulunmaz.

Kanal ve bar dolgularından oluşan istifin sedimanter özellikleri ve stratigrafi bağıntıları,
Örnekköy formasyonu üzerine ilerleyerek gölsel çökelimi sonlandıran olası örgü deltası-örgülü akarsu dolgulanmasını yansıtmaktadır (Göktaş, 2012).

Birimin Örnekköy formasyonuna göreli yaşı geç Orta Miyosen'dir.

Topçutepe formasyonu, Göktaş (2012)'ın Kocaçay havzasında tanımladığı Vişneli formasyonunun üst bölümünü oluşturan Doğancılar üyesinin karşılı̆̆ıdır.

\section{Ulucak Formasyonu}

Ulucak formasyonu, Çiçekliköy grubu istifinin çakı1taşı-kumtaş1-çamurtaşı topluluğundan yapılıalt bölümünü oluşturur. Birimin çalışma alanı içinde ayırtlanan yüzlekleri (Şekil 6A), Akdeniz vd. (1986)'nde Vişneli formasyonu, Sözbilir vd. (2011)'nde ise Kızılca formasyonu kapsamında haritalanmıştır.

Alttan üste tane boyu incelmesi gösteren istifin başlıca kayatürü bileşenleri, Spil (Manisa) Dağı ve Kemalpaşa Dağı yükseltilerini oluşturan Bornova flişi kapsamındaki Mesozoyik karbonat kayalarından türemiştir. Genel ayrışma rengi, açıkkoyu kırmızı arasında değişir. Çakıltaşlarının çoğu, kaba kumdan oluşan ara gereç destekli ve orta-kötü boylanmalıdır. Çakıl boyutları iri çakı1 ile ufak çakıl büyüklük sınırları arasında değişir. Çakıllı kumtaşlanı ile kumtaşları çoğunlukla masif olup orta-kötü boylanmalıdır. Çamurtaşı ve kumtaşı düzeylerinin sıklığı ve kalınlığı, tortul istifin üst bölümlerinde belirgin artış gösterir. Metrik düzeyler oluşturan kumlu çamurtaşı, açık pembemsi kahve ya da soluk turuncu renklerde, bütünüyle masif ve kötü boylanmalıdır. Kaba kumtaşı ve çakııltaşı arakatkıları, çamurtaşı egemen bölümlerde seyrek mercekler olarak bulunur.

Ulucak çevresindeki tortul istif, Spil Dağı yamaçları üzerinde güneye doğru gelişim gösteren örgülü akarsu egemen alüvyon yelpazesi tortullaşmasının ürünüdür.

İnceleme alanının kuzeybatısında yüzeyleyen Ulucak formasyonu, Bornova flişi içindeki Mesozoyik karbonat kaya kütlelerinden olan Beşpınar formasyonu (Akdeniz vd., 1986) ile Anadağ kireçtaşını (Akdeniz vd., 1986) açılı uyumsuzlukla üstler. Genelleştirilmiş stratigrafide, Örnekköy ve Ulucak formasyonları 


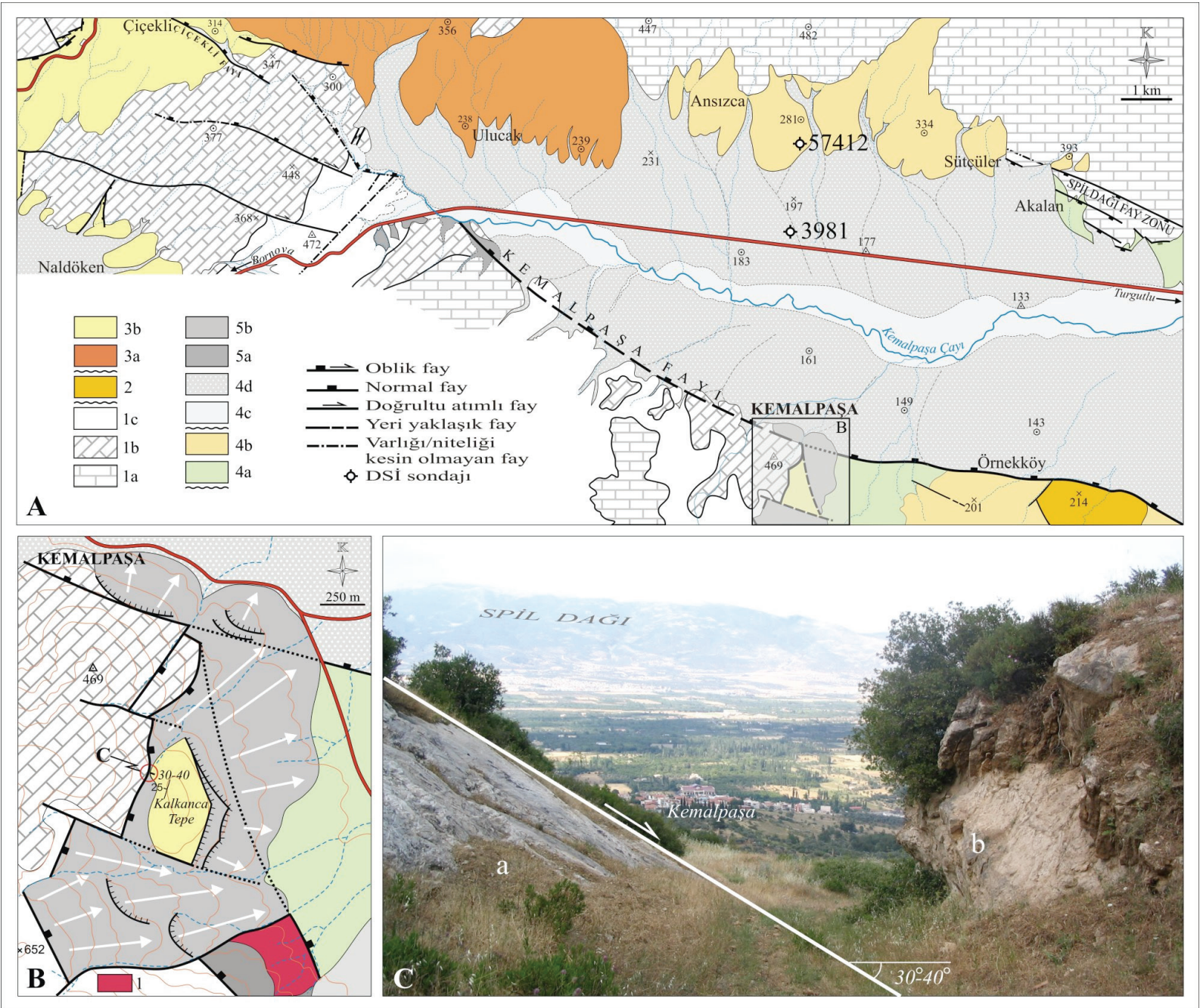

Şekil 6. A) Kemalpaşa kuzeyinin jeoloji haritası. 1. Bornova Fliş Zonu (a: Beşpınar fm. [Jura-Kretase], b: Anadağ kireçtaş1 [Üst Kretase], c: Belkahve fm. [Üst Kretase-Paleosen]), 2. Örnekköy fm. ve Topçutepe fm. (Orta Miyosen), 3. Çiçekliköy grubu (a: Ulucak fm., b: Yaka kireçtaşı [Üst Miyosen-Alt Pliyosen'in alt1]), 4. Gediz grubu (a: Çiniliköy fm. [Alt Pliyosen'in üstü-Pleyistosen], b: Kızılca fm. [Pleyistosen]), c: Akarsu çökelleri [Holosen], d: Alüvyon yelpazesi çökelleri [Holosen]), 5a. Yamaç molozu, 5b. Heyelan alanı); B) Kalkanca Tepe çevresinin jeoloji haritası. 1: Dereköy fm. (Diğer kaya birimi açıklamaları Şekil 4A'dadır), C) Kalkancatepe fayı. a: Anadağ kireçtaşı, b: Yaka kireçtaşı.

Figure 6. A) Geological map of northern part of the Kemalpaşa basin. 1. Bornova Flysch Zone (a: Beşpınar fm. [Jurassic-Cretaceous], b: Anadağ limestone [Upper Cretaceous], c: Belkahve fm. [Upper CretaceousPaleocene]), 2. Örnekköy fm. and Topçutepe fm. (Middle Miocene), 3. Çiçekliköy group (a: Ulucak fm., b: Yaka limestone [Upper Miocene-lowermost Lower Pliocene]), 4. Gediz group (a: Çiniliköy fm. [uppermost part of Lower Pliocene-Pleistocene], b: Klzllca fm. [Pleistocene]), c: Fluvial deposits [Holocene], d: Alluvial fan deposits [Holocene], 5a. Slope debris, 5b. Landslide area); B) Geological map of the Kalkancatepe area. 1. Dereköy fm. (See Figure 4A for explanations of other litho-units), $\boldsymbol{C}$ ) Kalkancatepe fault. a: Anadağ limestone, b: Yaka limestone.

arasında öngörülen açılı uyumsuzluk çalışma alanında gözlenmez. Çiçekliköy ve Kalkanca Tepe çevrelerinde yanal-düşey geçiş ilişkisiyle
Yaka kireçtaşı tarafindan üstlenen birim, Ulucak çevresinde Holosen alüvyon yelpazeleri tarafından açılı uyumsuzlukla örtülür. 
Yalçınlar (1953/54), Beşyol köyü çevresindeki (Şekil 2) eşdeğer çökellerde tanımladığ 1 Mastodon sp. bulgusuna dayanarak, bölgedeki Geç Miyosen (Ponsiyen) tortullaşmasına ilk kez değinmiştir. Kaya (1994) tarafindan Çiçekliköy’deki (Şekil 2) Ulucak formasyonu çökellerinde tanımlanan büyük memeli fosillerinin (Ceratotherium neumayri, Hipparion sp.) düşey dağılımı MN9-MN13 biyozonları arasındadır (11,1-4,9 my arasi: Steininger, 1999). Gediz Grabeni'nin KB uzantısındaki Halitpaşa yarı grabeninde yüzeyleyen çamurtaşı egemen gölsel istifin değişik düzeylerinde, Geç Miyosen'den (Türoliyen) erken Erken Pliyosen'e (erken Ruskiniyen) kadar yaşlandırılan memeli fosilleri tanımlanmıştır (Şen vd., 1989; Ferre, 1990; Kaya vd., 1998; 2004 ve bu çalışmalarda değinilen kaynaklar). Bölgesel biyokronoloji verilerine göre, alüvyon yelpazesi çökeliminin esas olarak Geç Miyosen'i kapsadığı ve Türoliyen'den itibaren gölsel çökellere yanal girik gelişim gösteren tortullaşmanın erken Erken Pliyosen sonlarına kadar devam ettiği kabul edilmiştir (Şekil 4).

\section{Yaka Kireçtaşı}

Akdeniz vd. (1986) tarafindan tanımlanan Yaka kireçtaşı istifi karbonat kayalarından oluşur (Şekil $6 \mathrm{~A}$ ve B). İstifin taban kesimindeki çamurtaşları, genellikle soluk sarı ya da açık kızıl-kahverenkli, masif, genellikle biyoturbasyonlu ve yersel olarak yüksek organik madde içeriklidir. Çamurtaşı düzeyleri içinde, desimetrik kalıllıklarda yumrulu kireçtaşı katmanları ve kaliş yumruları bulunur. Kalınçok kalın düzgün katmanlı olan kireçtaşı-dolomitik kireçtaşının ayrışma yüzeyi gri, taze kaya ise bej ya da açık gri renklidir. Katmanlanmanın giderek kalınlaştı̆g 1 üst bölümlerde, dallı tatlı su alglerinin oluşturduğu biyoklastik düzeyler ortaya çıkar.

Yaka kireçtaşı, Geç Miyosen havza kenarı tortullaşmasını yansitan Ulucak formasyonunun alüviyal çökelleriyle yanal giriktir ve kıyı gerisi çamurtaşlarını izleyerek kalıcı göl ortamında çökelmiştir.

Çiçekliköy güneyindeki yüzlekler, Üst Kretase yaşlı Anadağ kireçtaşına transgresif aşmayla yaslanır (Şekil 6A). Kalkanca Tepe çevresinde yüzeyleyen Yaka kireçtaşı ile Anadağ kireçtaşı arasındaki dokanak, düşük eğimli $\left(30^{\circ}-40^{\circ}\right)$ normal fay niteliğindeki Kalkancatepe fay1 tarafından belirlenmiştir (Şekil 6B ve C). Fay düzlemine yaklaştıkça, kireçtaşı ve çamurtaşı katmanlarının ortalama $25^{\circ}$ 'lik eğimlerle 'geriye çarpıldığı' gözlenir. Bölgenin bireşimsel stratigrafisinde açılı uyumsuzlukla birimin üzerinde yer alan Gediz grubu çökelleriyle Yaka kireçtaşının dokanağı çalışma alanında gözlenmez.

Gediz havzasının KB bölümünde, kireçtaş1 arakatkılı çamurtaşı istifiyle simgelenen gölsel tortullaşmanın, Türoliyen'den erken Ruskiniyen'e (erken Erken Pliyosen) kadar devam ettiği memeli fosil bulgulariyla kanıtlanmıştır (Kaya vd., 1998; 2004 ve bu çalışmalarda değinilen kaynaklar). Batı Anadolu'da birbirini izleyen iki evreli gerilme sürecini ayırdığı öngörülen geç Erken Pliyosen sıkışma fazında (Koçyiğit vd., 1999; Yılmaz, 2000; Bozkurt, 2000, 2003; Bozkurt ve Sözbilir, 2004, 2006; Kaya vd., 2004), gölsel istifin deforme olarak su üstüne çıktığı ileri sürülebilir.

Manisa-Saruhanlı alt havzasındaki Halitpaşa çevresinde tanımlanan "Develi formasyonu"nun ortaüst bölümleri ile "Halitpaşa formasyonu" (Kaya vd., 2004), gölsel istifin kireçtaşı aradüzeyleri kapsayan çamurtaşı egemen kesitini karşılar. Sözbilir vd. (2011)'nde, birimin eşleniği olan gölsel kireçtaşlanı Kızılca formasyonu içinde değerlendirilmiştir.

\section{KEMALPAŞA HAVZA DOLGUSUNUN STRATIGRAFISI}

Gediz Grabeni'nin yapısal-stratigrafik evrimini araştıran çok sayıdaki çalışmada, grabenin batı uzantısını oluşturan Kemalpaşa Havzası ele alınmamıştır (İztan ve Yazman, 1990; Cohen vd., 1995; Dart vd., 1995; Emre, 1996; Koçyiğit vd., 1996; Seyitoğlu ve Scott, 1996; Yılmaz vd., 2000; Seyitoğlu vd., 2000, 2002; Sözbilir, 2001, 2002; Bozkurt ve Sözbilir, 2004; Purvis ve Robertson, 2004, 2005; Çiftçi ve Bozkurt, 2007, 2008, 2009a,b, 2010; Şen ve Seyitoğlu, 2009; Çiftçi, 2013). Bu çalışmaların önemli bölümü, bakışımsız grabenleşmeyi biçimlendiren sıyrılma fay1 üzerindeki (supra-detachment) tortullaşmanın ve K-G genişlemenin son döneminde gelişen deformasyonun en iyi gözlendiği AlaşehirTurgutlu arasındaki güney kenarda yoğunlaşmıştır. GGSF'nin tavan bloğunda izlenen Pliyo-Kuvaterner istiflenmesinin genel düzeni, Gediz Grabeni ile 
Kemalpaşa havzası arasında yapısal-stratigrafik süreklilik bulunduğunu göstermektedir. $\mathrm{Bu}$ ilişki, Gediz Grabeni için önerilen litostratigrafilerin Kemalpaşa alt havzasıyla karşılaştıııldığı Şekil 7'de irdelenmiştir.

Kemalpaşa Havzası'nın Pliyo-Kuvaterner dolgulanması Gediz grubu (İztan ve Yazman, 1990) kapsamında incelenmiştir. Bu çalışmada, havzanın iki evreli yapılanmasıyla eşzamanlı gelişim gösterdiği kabul edilen Gediz grubu çökelimi, geç Erken Pliyosen-Pleyistosen ve Holosen dönemlerinde dolgulanan başlıca iki istife ayrılmıştır. Birinci istif düşük açılı normal faylar ve esas olarak GGSF, ikinci istif ise yüksek aç1l normal fay sistemleri tarafindan denetlenmiştir (Şekil 2). Havza oluşumu ve dolgulanmasının başlangıç zamanı ( 4,5-5 my önce), Kaya vd. (2004) ile Mayda vd. (2013)'nin biyokronolojik değerlendirmelerine dayanmaktadır (Şekil 8).

Bu çalışmada kabul edilen zamanstratigrafi sınırları içinde, Gediz grubu(GG) başlıca beş birimden oluşur. Şekil 8'de önerilen bireşimsel stratigrafi, Şekil 9'da sunulan çalışma alanı içinde ve ağırlıklı olarak Kemalpaşa alt havzasının batı kesiminde kurulmuş, Manisa-Saruhanlı alt havzasındaki DSİ sondaj verilerinden yararlanılarak geliştirilmiştir.

Gediz Grabeni'nin AlaşehirTurgutlu arasındaki güney kenarında dolgulanmış birinci evre istifinin alt bölümünü oluşturan kızılbordo renkli alüvyon yelpazesi çökelleri (GG1), Gediz havzasının B (Kemalpaşa) ve KB (ManisaSaruhanlı) bölümlerinde gözlenmez. Bu kesimlerdeki çöküntü alanları, eski Gediz Nehri ve yan kollarının boşaldığı gölsel havzalar olarak gelişimlerini geç Erken Pliyosen-Pleyistosen boyunca sürdürmüşlerdir. Akhisar ile Gölmarmara arasındaki Yemişli ve Kumkuyucak gölleri, Emiaralem vadisinin Holosen'de açılmasıyla suları Ege Denizi'ne boşalan büyük Pleyistosen gölünün kalıntılarıdır (Hakyemez vd., 2013).

Kemalpaşa Havzası'ndaki birinci evre istifinin alt bölümünü oluşturan Çiniliköy formasyonu (GG2) baskın olarak ince kırınt1l gölsel çökellerden oluşur (GG2.a) ve üste doğru flüviyo-deltaik kırınt1llara (GG2.b) derecelenir.
Gediz grubunun üçüncü birimi olarak, Çiniliköy formasyonu üzerine ilerleyerek gölsel tortullaşmayı büyük ölçüde sona erdiren alüvyon yelpazeleri (Kızılca formasyonu: GG3) dolgulanmıştır. En geç Pleyistosen'de GGSF önünde gelişen ve Kızılca formasyonu üzerinde uyumsuz konumlu yüzlek örtüler oluşturan kaba taneli alüvyon yelpazesi istifi (GG4) Armutlu formasyonu adıyla ayırtlanmıştır. Yüksek açılı Kemalpaşa normal fayının belirlediği Holosen evresinde, eksenel akarsu konumundaki Kemalpaşa Çayı ve yan kolları ile havzanın kuzey ve güney kenarlarında gelişimlerini sürdüren alüvyon yelpazeleri, Gediz grubunun beşinci ve son tortul dolgusunu (GG5) oluşturmaktadır (Şekil 8).

Gediz ve Büyük Menderes grabenlerinin stratigrafik bakışımlı supra-detachment istiflerinde, daha çok geç Villaniyen-erken Bihariyen mega zonlarını gösteren küçük memeli faunalarının tanımlandığı bilinmektedir (Ünay vd., 1995; Ünay, 1997; Ünay ve Bruijn, 1998; Ünay ve Göktaş, 1999; Sarıca, 2000, Ünay vd., 2003; Mayda vd., 2013). Ancak, Çobanisa çevresinde (Şekil 2) yüzeyleyen Çiniliköy formasyonunun flüviyodeltaik çökellerinde Mayda vd. (2013) tarafindan tanımlanan MN15 biyozonunun "genç" memelilerine dayanılarak, Gediz grubu tortullaşmasının geç Erken Pliyosen'de (geç Ruskiniyen) başladığı kabul edilmiştir (Şekil 8). Gediz ve Büyük Menderes graben dolgularındaki küçük memelilere yönelik biyokronolojik değerlendirmeler Toringiyen'e kadar uzanmaktadır (Ünay vd., 1995; Ünay, 1997; Ünay ve De Bruijn, 1998).

\section{Birinci Evre (Geç Erken Pliyosen-Pleyistosen)}

Kemalpaşa Havzası'ndaki dolgulanma sürecinin birinci evresi, havzayı güneyden sınırlayan GGSF'nin tavan bloğu üzerinde gelişmiştir. İnceleme alanında tabanı gözlenemeyen tortul istif, alttan üste göl-egemen Çiniliköy, alüviyal Klzılca ve alüviyal Armutlu formasyonlarından oluşur (Şekil 8). Birinci evre dolgularını kapsayan Kemalpaşa Havzası, Manisa il merkezi ile Turgutlu arasında uzanan verev/normal Manisa fay1 (Emre vd., 2005; Bozkurt ve Sözbilir, 2006; Özkaymak ve Sözbilir, 2008) tarafindan Holosen'de kesilerek Gediz Grabeni ana havzasından ayrılmıştır (Şekil 2). 


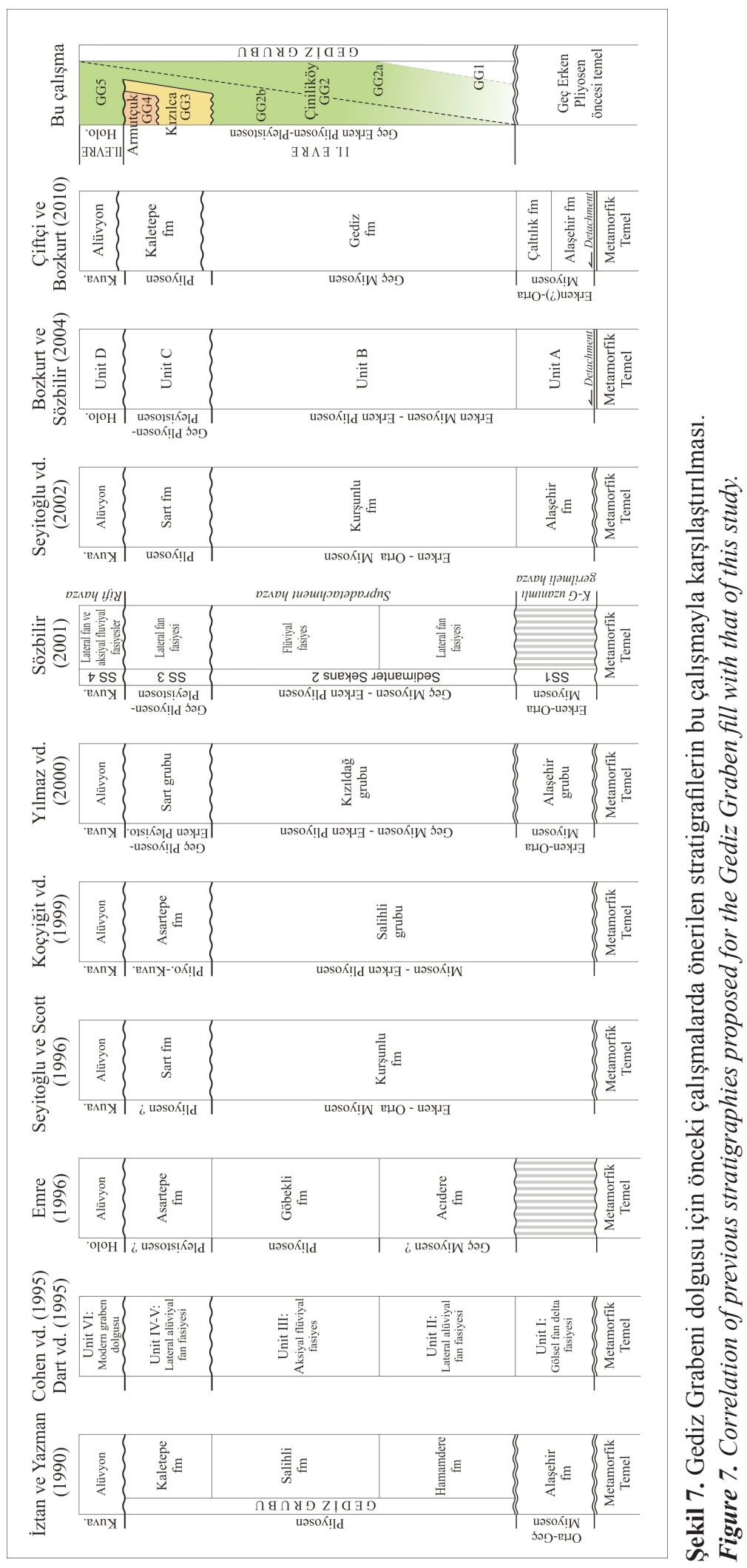




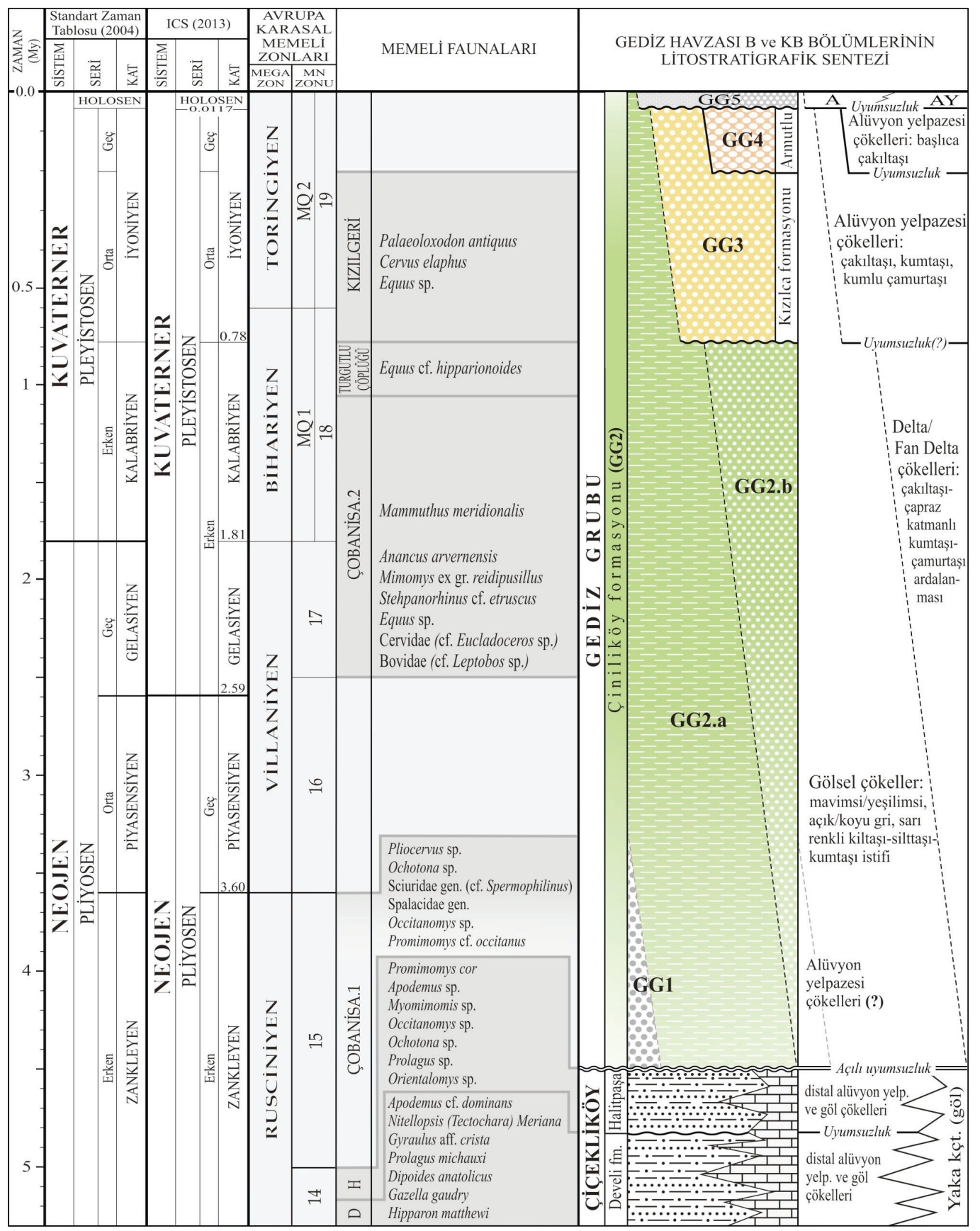

Şekil 8. Gediz havzasının B (Kemalpaşa alt havzası) ve KB (Manisa-Saruhanlı alt havzası) bölümleri için önerilen bireşimsel stratigrafi. GG1: Yanal alüviyal çökeller, GG2: Çiniliköy fm. (a: gölsel çökeller, b: Delta/fan delta çökelleri), GG3: Kızılca fm., GG4: Armutlu fm., GG5: Holosen çökelleri (A: Akarsu çökelleri, AY: Alüvyon yelpazesi çökelleri).

Figure 8. Syntetic stratigraphy proposed for the western (Kemalpaşa subbasin) and northwestern (Manisa-Saruhanlı subbasin) parts of Gediz basin. GG1: Lateral alluvial deposits, GG2: Çiniliköy fm. (a: lacustrine deposits, b: Deltalfan delta deposits), GG3: Klzllca fm., GG4: Armutlu fm., GG5: Holosen deposits (A: Fluvial deposits, AY: Alluvial fan deposits). 


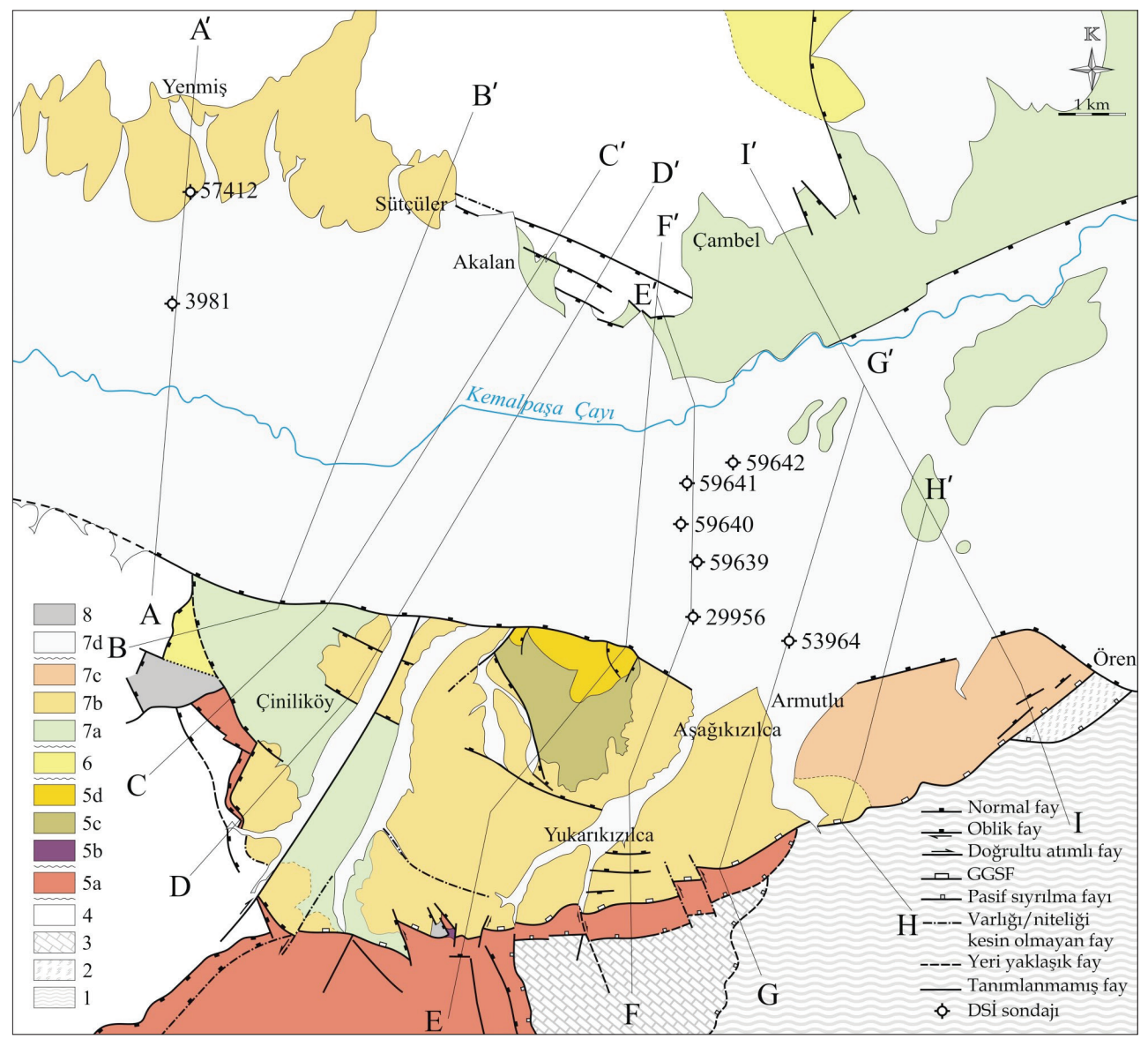

Şekil 9. Çalışma alanının yalın jeolojisi. 1. Menderes Masifi, 2. Kikladik kompleks, 3. Bodrum napı, 4. Bornova Fliş Zonu, 5. Kemalpaşa grubu (a: Dereköy fm, b: Yukarıkızılca volkaniti, c: Örnekköy fm, d: Topçutepe fm), 6. Yaka kireçtaşı, 7. Gediz grubu (a: Çiniliköy fm, b: Kızılca fm, c: Armutlu fm, d: Alüvyon), 8. Heyelan alanı.

Figure 9. Simplifiedgeological map of the study area. 1. Menderes Massif, 2. Cycladic complex, 3. Bodrum Nappe, 4. Bornova Flysch Zone, 5. Kemalpaşa group (a: Dereköy fm., b: Yukarıkızlca volcanics, c: Örnekköy fm., d: Topçutepe fm.), 6. Yaka limestone, 7. Gediz group (a: Çiniliköy fm., b: Klzılca fm., c: Armutlu fm., d: Alluvium), 8. Landslide area.

\section{Çiniliköy formasyonu}

Zayıf pekişmiş kiltaşı-silttaş1-kumtaşı topluluğundan oluşan tortul istif, üste doğru artan sıklıkta çakıltaşı ve çapraz katmanlı kumtaşı aradüzeyleri kapsar. Göktaş (2012) tarafından tanımlanan birimin adı Çiniliköy’den alınmıştır (Şekil 5).

$\mathrm{Az}$ belirgin katmanlı ve masif çamurtaşı litofasiyesi tortul istife egemendir. Mavi, yeşil, sarımsı bej, açı/koyu gri renkli desimetrik ve metrik kalınlıklardaki düzeylerin ardalanması tipiktir. Seyrek olarak soluk kırmızı renkli çamurtaşı düzeylerine rastlanır. Gölsel istif içinde sıklıkla ortaya çıkan, siyahımsı koyu gri renkli kiltaşı-silttaşı düzeyleri yüksek oranda organik gereç içerir (Şekil 10). Kalın çamurtaşı düzeyleri ile birlikte bulunan ince-orta taneli kumtaşı arakatmanları masif ve zayıf pekişmiştir.

İnce kırıntılı istif, üste doğru sıklığı ve kalınlığı artan flüviyal çakıltaşı-çakıllı kumtaş1kumtaş1 arakatmanları kapsar (Şekil 11). Çakıltaşı, çoğunlukla küçük çakıl büyüklük sınırları içinde, ara gereç (kaba taneli kum) destekli, genellikle zayıf pekişmiş ve orta-iyi boylanmıştır. Çakıllar genellikle yuvarlaktır. Kaba taneli kumtaşı, yersel çapraz katmanlı ve yüksek dokusal olgunluktadır. İstifin üst 

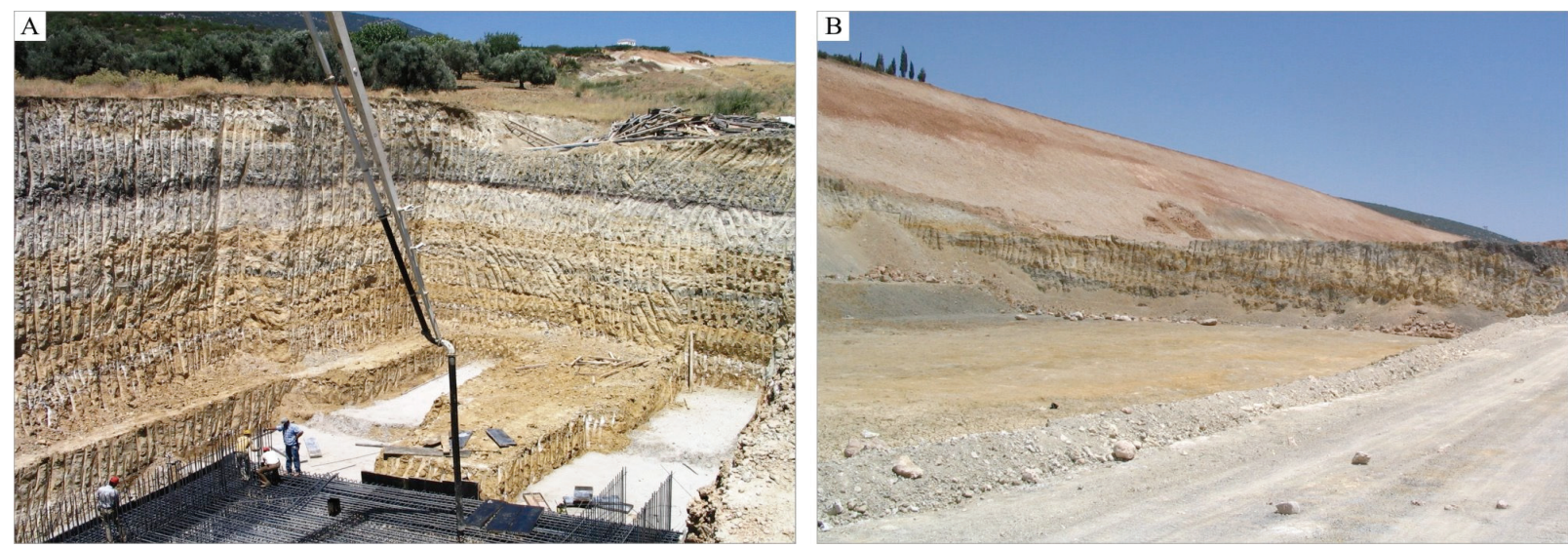

Şekil 10.Sütçüler ile Akalan köyleri arasındaki demiryolu inşaatı yarmalarında gözlenen Gediz grubu çökelleri. A) Çiniliköy formasyonu gölsel çökelleri, B) Altta Çiniliköy, sol üstte Kızılca formasyonu. Genel katman eğimleri, Holosen havzasını güneyden belirleyen aktif Kemalpaşa fayına doğrudur.

Figure 10. Gediz group deposits exposed on the excavated walls of the railway construction between Sütçüler and Akalan villages. A) Lacustrine deposits of Çiniliköy formation, B) Çiniliköy formation (lower part) and Kizllca formation (upper left side). Layers are normally inclined towards the active Kemalpassa fault, southern limit of the Holocene basin.

kesimleri, az belirgin çapraz katmanlı ya da masif kumtaşı düzeyleri ile birlikte bulunan, $5-15 \mathrm{~cm}$ arası büyüklüklerde iyi yuvarlanmış çakıllardan yapılı çakıltaşı düzeylerinden oluşur.

Gölsel ortamda gelişen ince kırıntılı tortullaşma, Çiniliköy formasyonunun özellikle alt bölümüne egemendir. Üst bölümlerde artış gösteren çakı1taşı ve çapraz katmanlı kumtaşı arakatmanları, paleoredüksiyonu yansitan renkleri, içerdikleri pelesipod (Unio sp.), tatlı su gastropodu ve balık dişleriyle sualtı tortullaşmasını yansıtır. $\mathrm{Bu}$ çökel topluluğu, göle açılan delta ve yelpaze deltalarının ürünleri olarak yorumlanmıştır. Gediz havzası genelinde flüviyo-deltaik dolgulanmayla sınırları giderek daralan göller, bazı alanlarda günümüze kadar varlığını sürdürmüştür. Kemalpaşa Havzası'ndaki "Ulucak", "Yenmiş" ve "Nemrut" gibi prehistorik yerleşimler (Şekil 2), günümüzde alüvyon yelpazeleriyle örtülmüş olan Pleyistosen'den kalıtsal gölün kıyılarında kurulmuştur. Söz konusu yerleşimlerin 7800-7900 yıl önce terk edilmiş olması, Gediz Nehri'ne boşalan gölün kurumasıyla ilişkilendirilmiştir (Hakyemez vd., 2013).

$$
\text { Çalışma alanında Çiniliköy }
$$

formasyonunun stratigrafik tabanı gözlenmez. Gölsel çökeller, havzanın kuzeyinde yüzeyleyen Jura-Kretase yaşlı Beşpınar formasyonuna doğrudan yaslanır (Şekil 12). Akalan çevresinde, istifin üst bölümünü karakterize eden flüviyodeltaik tortullaşma gelişmemiştir.

Manisa-Saruhanlı alt havzasındaki DSİ sondajlarının değerlendirilmesi sonucunda, gölsel istifin -taban kırıntılıları aracıllğıyla- (Geç?) Miyosen kireçtaşları ve Mesozoyik karbonat kayaları üzerine uyumsuzlukla geldiği anlaşılmıştır. $\mathrm{Bu}$ stratigrafi ilişkisi, Gediz havzasının $\mathrm{B}$ ve $\mathrm{KB}$ bölümlerinde gelişen Gediz grubu tortullaşmasının doğrudan gölsel çökellerle başladığını, graben ekseninde kuzeybatıya doğru akan akarsu sisteminin (eski Gediz Nehri) değinilen göle boşaldığını göstermektedir (Hakyemez vd., 2013). Geç Miyosen-erken Erken Pliyosen yaşlı Çiçekliköy grubu kayabirimleri ve Dereköy formasyonu ile dokanaklar, GGSF ve batı uzantısındaki düşük açılı normal fay sistemi (Kalkancatepe fayı) tarafindan belirlenmiştir (Şekil 13). Kizilca formasyonu tarafindan uyumsuzlukla üstlenen birimin çalışma alanı içindeki yüzlekleri, yersel olarak kalık (inaktif) heyelan kütleleri ve Holosen alüvyonlarıyla örtülmüştür.

Gediz Grabeni'nde MTA tarafindan yürütülen önceki çalışmalarda, gölsel birimin yanal eşdeğeri kabul edilen akarsu sisteminin taşkın düzlüklerinde bulunmuş memeli fosilleri ağırlıklı olarak Erken Pleyistosen yaşları vermiştir. Turgutlu ile Alaşehir arasında tanımlanan küçük memeli 


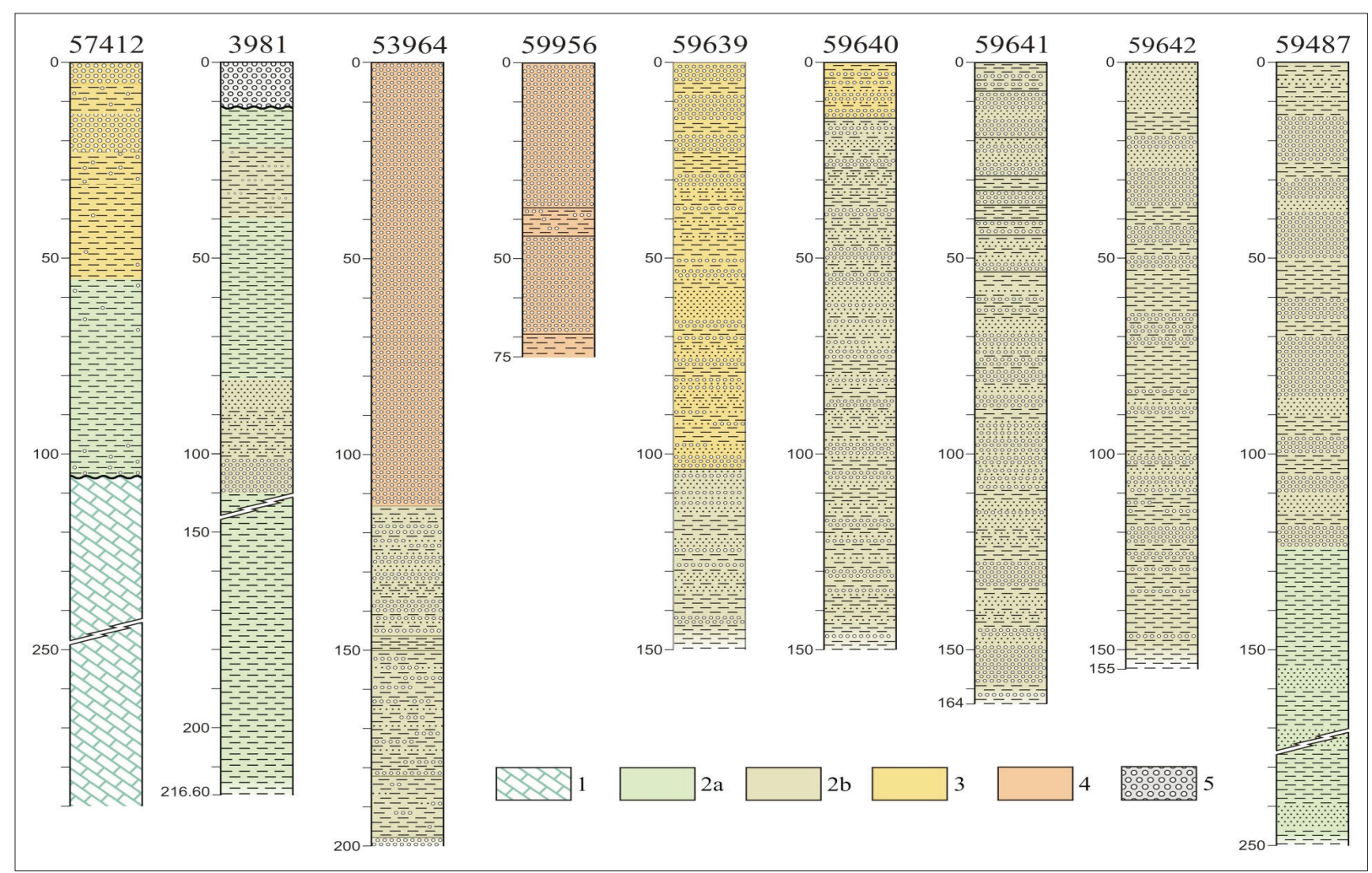

Şekil 11. Kemalpaşa havzasında incelenen DSİ kuyu logları ve yalınlaştırılmış çökel fasiyesleri. 1. Beşpınar fm., 2. Göl çökelleri (a: Çiniliköy fm “gölsel”, b: Çiniliköy fm. "flüviyo-deltaik”), 3. Çamur düzlüğü(?) ve/veya distal fan çökelleri (Kızılca fm.), 4. Kaba taneli alüvyon yelpazesi çökelleri (Armutlu fm.), 5. Holosen Alüvyon yelpazesi çökelleri. Sondaj lokasyonları Şekil 1B'dedir.

Figure 11. Studied logs of wells drilled in the Kemalpaşa basin and simplified sedimentary facies of the logs. 1 . Beşpınar fm., 2a. Lacustrine deposits of Çiniliköy fm., 2b: Fluvio-deltaic deposits of Çiniliköy fm., 3. Mud flat (?) and/or distal fan deposits (Klzllca fm.), 4. Coarse-grained alluvial fan deposits (Armutlu fm.), 5. Holocene Alluvial fan deposits. See Figure 1B for locations of drill-holes.

fosillerinin (Mimomys pliocaenicus, Mimomys $\mathrm{cf}$. ostramosensis, Microtus sp.) dağılımı, MN17-18 biyozonlarını karşılayan geç Villaniyen ile erken Bihariyen arasındadır (Ünay, 1997). Sarıca (2000) tarafindan, Salihli batısında, Çaltılı çevresindeki eşitli düzeylerde tanımlanan Apodemus cf. sylvaticus aynı megazonları gösterir. Saraç (2003)'a göre, Salihli-Sartmustafa faunası (Mimomys cf. Ostramosensis, Lagurini sp., Tibericola sp., Apodemus sp.) erken Villaniyen'e (MN16) inebilir. Turgutlu çevresinde, doğal agrega ve tuğla-kiremit hammaddesi olarak kullanılan Çiniliköy formasyonu çökelleri (Turgutlu formasyonu: Paton, 1992) iyi korunmuş büyük memeli fosilleri yönünden oldukça zengindir. $\mathrm{Bu}$ çevredeki hammadde ocaklarında bulunan Erken Pleyistosen'de yaşamış büyük memelilere ait molar dişleri, Anancus arvernensis (geç Villaniyen) ve Mammuthus meridionalis (Bihariyen) olarak tanımlanmıştır (Mayda vd., 2013). Turgutlu çöplüğünde (Şekil 1B) bulunan Equus cf. hipparionoides geç Bihariyen'e (MN18) işaret eder ve 1.0 my'a tarihlenir (Mayda vd., 2013). Çobanisa köyü çevresindeki (Şekil 1B) flüviyo-deltaik çökellerde Mayda vd. (2013) tarafından tanımlanan büyük memeli topluluğunun (Anancus arvernensis cf. alexeevae, Mammuthus meridionalis meridionalis, Stephanorhinus etruscus, Equus aff. major, cf. Eucladoceros sp., cf. Sivatherium sp., cf. Leptobos sp.) 


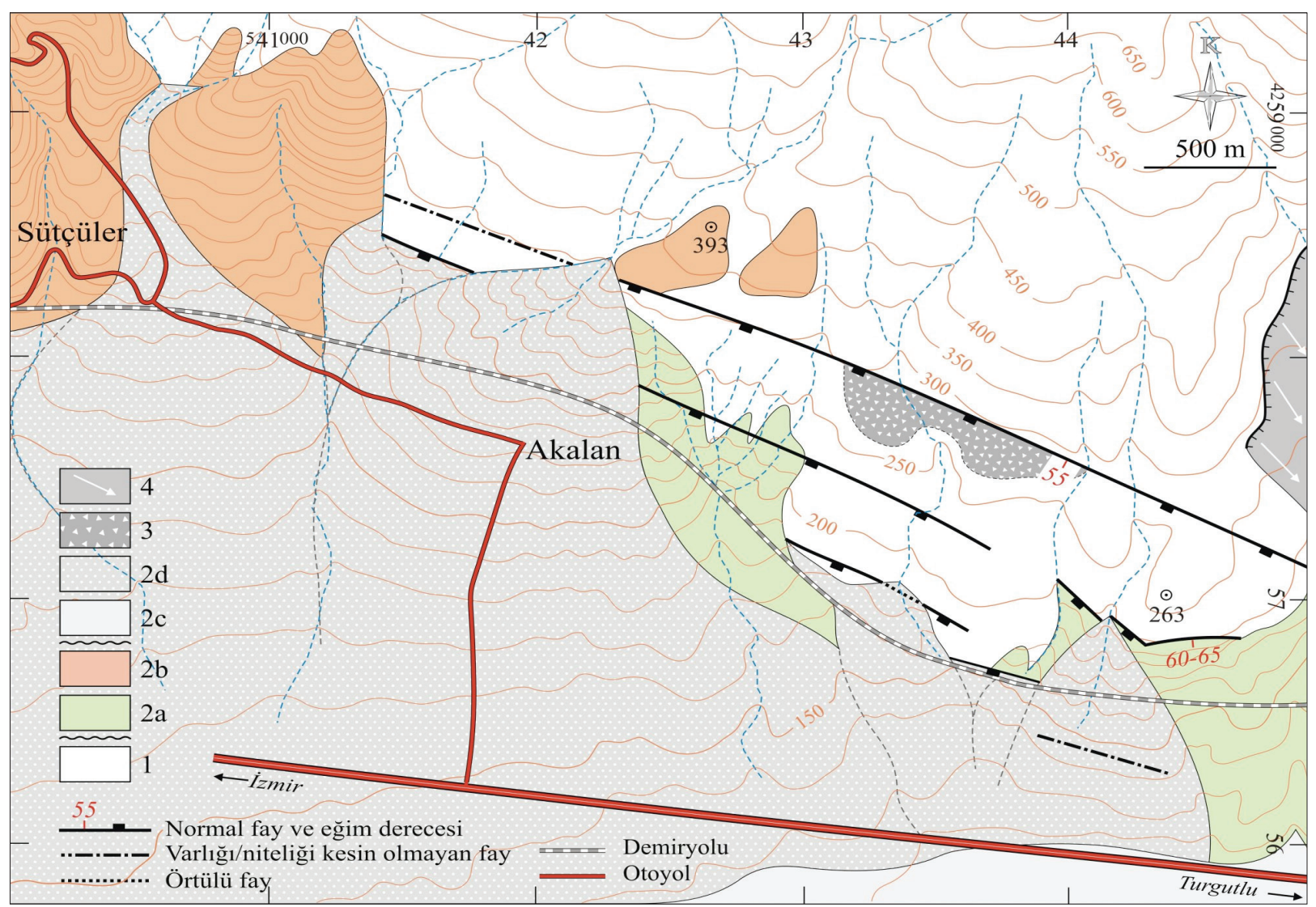

Şekil 12. Kemalpaşa havzasının kuzey kenarını temsil eden Akalan çevresi ve Spil Dağı fay zonunun jeoloji haritası.

1. Beşpınar fm., 2: Gediz grubu (a: Çiniliköy fm., b: Kızılca fm., c: Kemalpaşa Çayı'nın akarsu çökelleri, d: Alüvyon yelpazesi çökelleri), 3. Yamaç molozu, 4. Heyelan alanı.

Figure 12. Geological map of the area around Akalan and Spil Dağl fault zone, the northern margin of the Kemalpaşa basin. 1. Beşpinar fm., 2: Gediz group (a: Çiniliköy fm., b: Klzılca fm., c: Fluvial deposits of Kemalpaşa Stream, d) Alluvial fan deposits, 3. Slope debris, 4. Landslide area.

yaşı Erken Pleyistosen'dir. Aynı çalışmada tanımlanan Mimomys ex. gr. reidi-pusillus, erken Erken Pleyistosen'e (geç Villaniyen) karşıllk gelen MN 17 biyozonunun ikinci yarısina (1,9-2.1 my arası) aittir. Çobanisa çevresinde Mayda vd. (2013) tarafından yeniden tanımlanan en yaşlı küçük memeli faunas1 (Pliocervus sp., Ochotona sp., Promimomys cf. occitanus, Occitanomys sp.) geç Ruskiniyen'i (geç MN15) gösterir (Şekil 8: Çobanisa 1 faunası).

\section{Kizilca formasyonu}

Alttan üste tane boyu kabalaşması gösteren istif, ağırlıklı olarak çakıltaşı-kumtaşı topluluğundan oluşur. Birimin adı, ilk kez Sözbilir vd. (2011) tarafından kullanılmıştır. Aynı adlamayı kullanan Göktaş (2012), birimin zaman-kayastratigrafik kapsamını değiştirmiştir. Sözbilir vd. (2011)'nin Kızılca formasyonu (Orta-Üst Miyosen) olarak haritaladığı alan içinde, Göktaş (2012) tarafindan Örnekköy ve Topçutepe formasyonları (Orta Miyosen), Çiçekliköy grubu kaya birimleri (Üst Miyosen-Alt Pliyosen'in alt1), Gediz grubu kapsamındaki Çiniliköy ve Kızılca formasyonları (Alt Pliyosen'in üstü-Pleyistosen) ayırtlanmıştır.

Kizılca formasyonu, kirmızıms1kahverenkli bir istifle simgelenir. Kanal dolgusu çakıltaşları, küçük çakıl büyüklük sınırları içindeki yuvarlak-yarı yuvarlak çakıllardan oluşur. Kötü boylanmış kumtaşı-kumlu çamurtaşı topluluğu, istifin alt bölümlerinde masif ve kalın düzeyler olarak bulunur. Tektonik denetimli tortullaşma sürecinde, i) havzayı güneyden sınırlayan GGSF'ye doğru 
geri çarpılan katman eğimleri sistematik olarak artar ve "ters sürüme kıvrımı"na (rollover antiklin) benzer bir yapı ortaya çıkar (Şekil 14), ii) stratigrafik olarak alttan üste ve GGSF'ye doğru ortalama çakıl boyutları giderek büyür; iyi yuvarlanmış çakıllardan oluşan akarsu çökellerinin yerini, küt köşeli-yarı yuvarlak iri çakıl ve 40-70 cm arası blokları değişen oranlarda kapsayan moloz/çamur akması çökelleri alır.

Tortul istif, havzanın güney kenarından kuzeye ve Spil Dağı eteklerinden güneye doğru gelişerek Çiniliköy gölsel havzasına açılan alüvyon yelpazesi tortullaşmasını yansıtır. Havzanın güneyinde, GGSF önünde gelişen örgülü akarsu egemen alüviyal istifin alttan üste tane boyu kabalaşması göstermesi, sintektonik tortullaşmanın 'ilerleyen' karakteri nedeniyledir.

Kızılca formasyonu, Çiniliköy formasyonu üzerine uyumsuzlukla gelir (Şekil 5). Dereköy formasyonuyla dokanaklar, doğrultu atımlı faylarla ötelenmiş GGSF ve Kalkancatepe fayı tarafindan belirlenmiştir (Şekil 5). Havzanın kuzeyinde Beşpınarformasyonu, güneyde ise Orta Miyosen yaşl1 Örnekköy formasyonu üzerinde açılı uyumsuzdur. Kemalpaşa normal fayı, Örnekköy çevresinde kestiği Kızılca formasyonu ile tavan blokta kuzeye doğru gelişimlerini sürdüren Holosen alüvyon yelpazeleri arasında aktif tektonik sinır oluşturur.

Çalışma alanı içinde fosil bulgusu yoktur. Birimin Manisa-Saruhanlı alt havzasındaki Kızılgeri Tepe çevresinde (Şekil 2) yüzeyleyen olası eşleniklerinde, Orta Pleyistosen'i gösteren büyük memeli fosillerinin (Palaeoloxodon antiquus Falconer ve Cautley, Cervus elaphus Linné, Equus sp.) tanımlandığı bilinmektedir (Şahinci, 1976).

\section{Armutlu formasyonu}

Alttan üste kaba çakıltaşlarından oluşan birim, Sözbilir vd. (2011)'de Sütçüler formasyonu adıyla tanımlanmıştır (Şekil 5). Havzanın kuzeyindeki Sütçüler köyü çevresinde yüzeyleyen alüvyon yelpazesi dolguları, bu çalışmada Kızılca formasyonu kapsamında değerlendirildiğinden birimin ismi değiştirilmiştir.

Koyu kızıl-kahve renkli istif, baskın olarak örgütlenmemiş iri çakıltaşlarından oluşur.
Metrik kalınlıklardaki düzeylerin alt ve üst sınırları belirsizdir. Kötü boylanmış, masif ve kaba taneli kumtaşı düzeylerinin araya girmesiyle, katmanlanma az çok belirginleşir. Genel olarak zayıf pekişmiş olan düşük dokusal olgunluktaki çakıltaşları, çoğunlukla tane destekli ve ara gereç dolguludur. Çoğu küt köşeli-yarı yuvarlak ve levhamsı şekilli olan çakıllar, ağıllıklı olarak Menderes Masifi kaya birimlerinden türemiştir.

Havzanın yalnızca güney kenarında, GGSF tavan bloğunda ayırtlanan tortul istif, Kızılca formasyonu üzerinde gelişen alüvyon yelpazesi çökeliminin ürünüdür. Ören ile Armutlu arasında alüviyal istifi kesen Kemalpaşa fayının tavan bloğunda kalan bölüm Holosen yelpazeleriyle örtülmüştür. Yüksek çakıl konsantrasyonlu moloz akmalarının oluşturduğu örgütlenmemiş çakıltaşları, alüviyal sistemin proksimal kesimlerinde gelişen hızlı depolanmanın ürünleridir. Sıyrılma fayı üzerinde gelişen birinci evre, Armutlu formasyonunun çökeldiği alanda eksiksiz temsil edilmektedir. GGSF üzerindeki maksimum siyrilma ve birinci evreye ait en kalın sintektonik depolanma, fay düzlemi eğiminin $17,5^{\circ}-25^{\circ}$ arasında olduğu Ören ile Kızılca arasında gelişmiştir.

Sıyrılma fayı üzerinde gelişen birinci evrenin son ürünü olarak alttan ve üstten uyumsuzluk yüzeyleriyle sınırlanmış olan birim, Gediz havzasının bireşimsel stratigrafisinde Kızllca formasyonu ile ikinci evrenin Holosen dolguları arasında yer alır. Havzanın güneyinde yüzeyleyen Kikladik Kompleks ve Menderes Masifi kaya birimleri ile dokanaklar GGSF tarafından belirlenmiştir. GGSF önünde suralanan heyelanlar (Şekil 3), Emre vd. (2005)'nde önerilen Holosen aktivitesinin ürünleri olabilir. Altta bulunan Kızılca formasyonuyla ilişki açık olmamakla birlikte, GGSF'nin tetiklediği tortullaşma enerjisindeki ani artışa bağlı olarak gelişen kaba taneli çökelim, iki alüviyal birim arasında olası bir uyumsuzluğu düşündürür. Kemalpaşa fayının Armutlu ile Ören arasındaki bölümü, Armutlu formasyonu ile genelleştirilmiş stratigrafide uyumsuzlukla üste gelen Holosen alüviyal çökelleri arasında dokanak oluşturur (Şekil 5). 


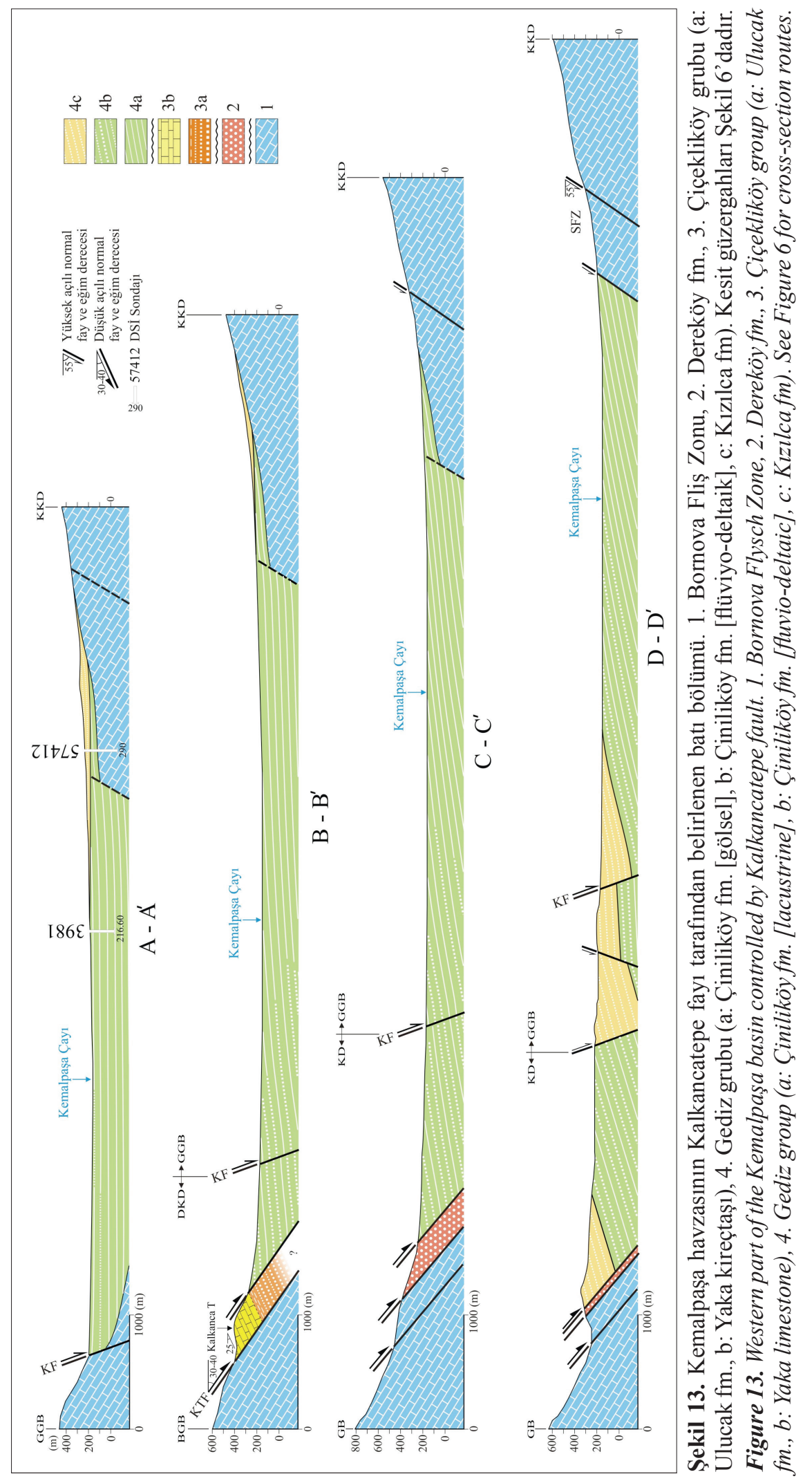




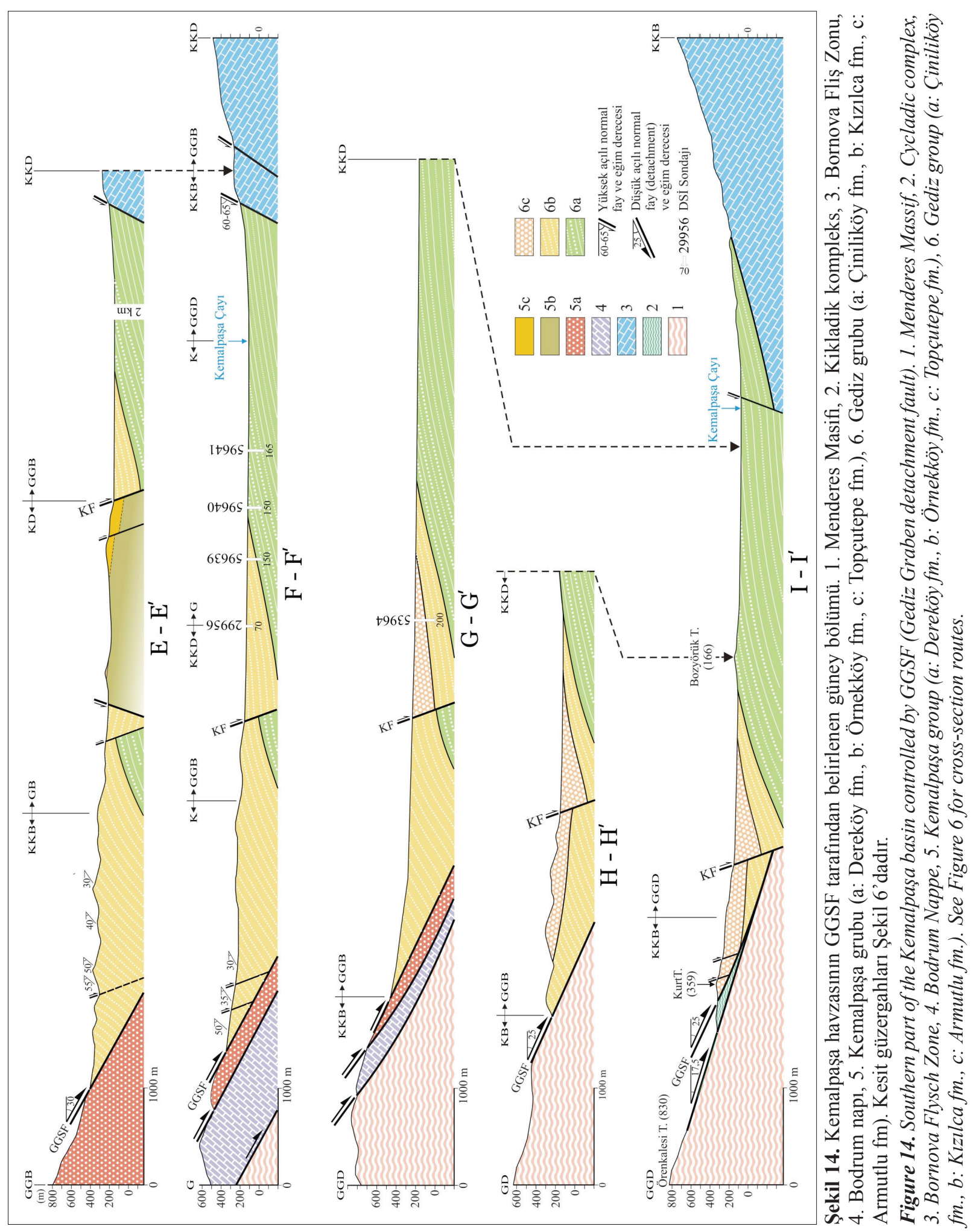




\section{İkinci Evre (Holosen)}

Gediz havzası genelinde ikinci evre havza oluşumu, Turgutlu'dan batıya ve kuzeybatıya çatallanarak Gediz grubunun birinci evre istifini kesen yüksek eğimli normal faylar tarafindan belirlenmiştir (Şekil 2). Kemalpaşa Havzası'nın birinci evre dolgusu üzerinde aç1lan Holosen havzas1, Turgutlu'dan Kemalpaşa'ya doğru kuzeye içbükey uzanan Kemalpaşa verev-normal fayı tarafindan belirlenmiştir (Şekil 15). Sözbilir vd. (2011)'ne göre, sağ yanal bileşenli Kemalpaşa normal fayının kuzeye doğru olan eğim aç1s1 $70^{\circ}$ 'dir. Havza, GGSF'nin tavan bloğunda sintetik bir yapı konumundaki Kemalpaşa fayı tarafından biçimlendirilmiş olmakla birlikte, kuzey kenarı kısmen belirleyen Spil Dağı aktif fay zonunun (Sözbilir vd.,
2011) işlemesiyle bağıl simetri kazanmıştır (Şekil 15). BKB genel gidişli Spil Dağı fay zonunu oluşturan verev-normal fayların kademeli gelişimi, ana fayın tavan bloğu üzerinde güneye taşınmayı yansıtır. Fay düzlemlerinin GB yönlü eğim açıları $55^{\circ}$ ile $65^{\circ}$ arasında değişir (Şekil 12). Havzanın kuzeyinde bulunan DKD gidişli Sancakliiğdecik fayı, Çiniliköy flüviyo-deltaik çökellerini yükseltmiş ve Kemalpaşa Çayı'nın fay düzlemine doğru göçüne neden olmuştur. BKB uzanımlı Çobanisa fayı, temel kayaları ile Çiniliköy formasyonu arasında sınır oluşturmuş ve tavan blok üzerinde çökelmekte olan Holosen yelpazelerinin doğuya gelişimlerini denetlemiştir. Kemalpaşa fayı önünde kuzeye doğru gelişmekte olan alüvyon yelpazeleri, Spil Dağı fay zonu önünde güneye doğru gelişen yelpazelerle karşılanmaktadır.

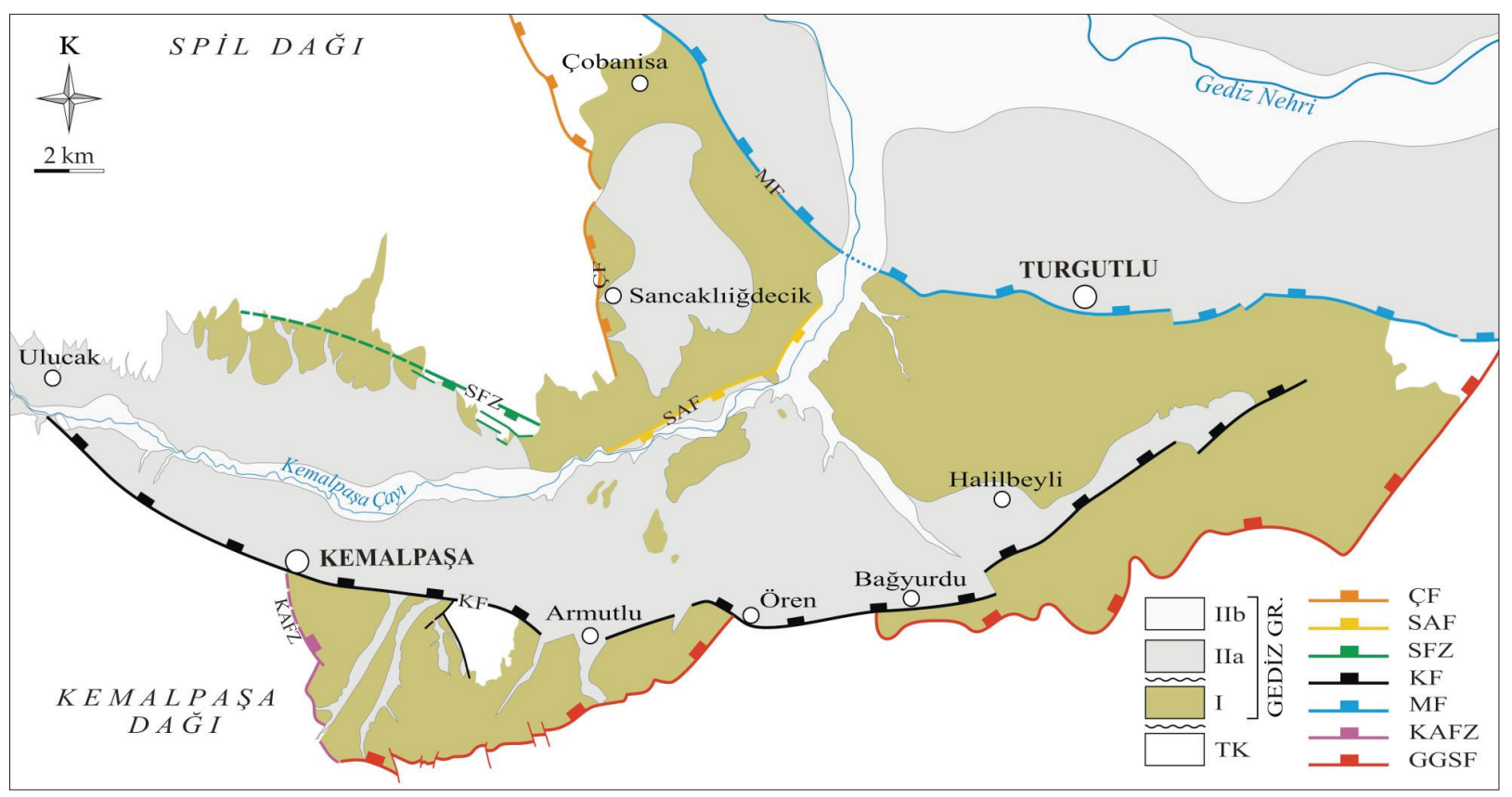

Şekil 15. Kemalpaşa havzasının birinci ve ikinci evre dolgulanmalarını belirleyen normal fay sistemleri. TK: Kemalpaşa havzasının tabanında yer alan 5 my'dan yaşlı temel kayaları, I: Gediz grubu birinci evre (geç Erken Pliyosen-Pleyistosen) çökelleri, II: Gediz grubu ikinci evre (Holosen) çökelleri (a: Alüvyon yelpazesi, b: Akarsu). GGSF: Gediz Grabeni sıyrılma fayı, KAFZ: Kalkancatepe fay zonu, MF: Manisa fayı, KF: Kemalpaşa fayı, SFZ: Spil Dağı fay zonu, SAF: Sancaklıiğdecik fayı, ÇF: Çobanisa fayı.

Figure 15. Fault systems controlling the first and second deposition phases in the Kemalpaşa basin. TK: Basement rocks of the Kemalpaşa basin older than 5 Ma. I: First phase (late Early Pliocene-Pleistocene) deposits of the Gediz group, II: Second phase (Holocene) deposits of the Gediz group (a: Alluvial fan, $b$ : Fluvial). GGSF: Gediz Graben detachment fault, KAFZ: Kalkancatepe fault zone, MF: Manisa fault, KF: Kemalpaşa fault, SFZ: Spil Dă̆l fault zone, SAF: Sancakliiğdecik fault, ÇF: Çobanisa fault. 
Modern Kemalpaşa Havzası, Holosen riftleşmesi sırasında kırılan Manisa normal fayının “doğu bölümü” (Özkaymak ve Sözbilir, 2008) tarafından Gediz ana havzasından ayrılmıştır (Şekil 15). Çiçekli Çayı'ndan itibaren doğuya akarak Gediz Nehri'ne birleşen Kemalpaşa Çayı, doğal yatağında aktığı yerlerde, düşük sinüslü menderesler yaparak örgülü akarsu çökellerini dolgulamaktadır.

\section{SONUÇLAR}

Gediz Grabeni'nin batı uzantısını oluşturan Kemalpaşa Pliyo-Kuvaterner havzasının tabanında, Menderes Masifi, Kikladik Kompleks, Bornova Fliş Zonu ve Bodrum napı kaya birimleri ile geç Erken Pliyosen'den yaşlı Neojen çökelleri bulunur. Neojen temel, Erken-Orta Miyosen yaşlı Kemalpaşa grubu kapsamında yer alan Dereköy, Örnekköy ve Topçutepe formasyonları ve Yukarıkızılca volkaniti ile Geç Miyosenerken Erken Pliyosen yaşlı Çiçekliköy grubunu oluşturan Ulucak formasyonu ve Yaka kireçtaşıyla simgelenir.

Havza tabanındaki en genç Neojen birimi, üst bölümü erken Erken Pliyosen yaşlı Halitpaşa formasyonuna (Kaya vd., 2004) karşılık gelen Yaka kireçtaşıdır (Şekil 8). Bölgesel ölçekte açılı uyumsuzlukla üstleyen Gediz grubu istifinde tanımlanmış en yaşlı memeli fosil topluluğu ise geç Erken Pliyosen'i (geç MN15: Mayda vd., 2013) göstermektedir (Şekil 8). Geç Miyosenerken Erken Pliyosen yaşlı Çiçekliköy grubu ile geç Erken Pliyosen-Güncel Gediz grubunu ayıran açılı uyumsuzluğun, önceki çalışmalarda önerilen kısa süreli sıkışma fazına karşılık gelebileceği; bu sırada deforme olan Yaka kireçtaşının su üstüne çıkarak aşınmaya başladığı önerilmiştir.

Kemalpaşa havzasının yaklaşık 5 my önce GGSF denetiminde açıldığı ve Gediz grubu tortullaşmasının, geç Erken PliyosenPleyistosen ve Holosen dönemlerini kapsayan başlıca iki evrede geliştiği kabul edilmiştir. $\mathrm{Bu}$ değerlendirme, Batı Anadolu'da Miyosen'den Günümüz'e kadar süren K-G gerilmenin yaklaşık olarak son 5 milyon yılda arttığını ve toplam gerilmenin önemli bölümünü kapsayan bu dönemin başında D-B grabenlerin oluştuğunu ileri süren çalışmalarla (Yılmaz vd., 2000; Bozkurt, 2001; Sözbilir, 2001; Taymaz v.d., 2001 ve bu çalışmalarda değinilen kaynaklar) uyumludur. Gediz Grabeni’nde yürütülen önceki çalışmaların sonuçlarıyla karşılaştırıldığında, Kemalpaşa havzasında birinci evrenin başlangıcı ve tektonik denetimli istiflenmenin sıralı düzeni konusunda yeni önerilerde bulunulmuştur. Alttan üste Çiniliköy, Kızılca ve Armutlu formasyonlarının simgelediği birinci evre dolgulanması, bakışımsız havza oluşumunu güneyden belirleyen GGSF'nin tavan bloğu üzerinde gelişmiştir. Havzanın kuzey kenarındaki Akalan çevresinde yüzeyleyen Çiniliköy gölsel çökellerinin temel kayalarına transgresif aşmayla doğrudan yaslanması, havzanın bakışımsı yapılanması yaklaşımını destekleyebilir.

GGSF'nin birinci evre tortullaşmasını denetlediğini gösteren veriler şunlardır: i) Gölsel çökellerle başlayan Çiniliköy formasyonu alttan üste tane boyu kabalaşması göstermekte ve çakıltaşı-çapraz katmanlı kumtaşı topluluğunun simgelediği flüviyo-deltaik çökellerle sona ermektedir. ii) alüviyal Kızılca istifinde, GGSF yönünde giderek artan katman eğimleri 'ters sürüme kıvrımı' oluşturmakta; alttan üste ve GGSF'ye doğru, yuvarlak küçük çakıllardan yapılı örgülü akarsu çökellerinin yerini, küt köşeli-yarı yuvarlak iri çakıı ve blokları değişen oranlarda içeren moloz akması çökelleri almaktadır (Şekil 14).

Ören'den Kurudere'ye doğru, GGSF'nin tavan bloğundaki birinci evre dolgusunun yanaldüşey dağ 11 mı ve sinsedimanter deformasyondan anlaşıldığı kadarıyla, sıyrılma düzlemindeki eğim artışına paralel olarak düşey atım miktarı ve toplam çökel kalınlığı azalmaktadır. Kurudere doğusunda $30^{\circ}$ 'nin üzerine çıkan fay düzlemi eğimleri Ören ile Yukarıkızılca arasında ortalama 20-25'ye indirgenir (Emre vd., 2005) ve ayn1 yönde yüzeyleyen birimler yaşlıdan gence doğru sıralanır (Şekil 5 ve 14).

Gediz havzasının B (Kemalpaşa) ve KB (Manisa-Saruhanlı) bölümlerinde gelişen Gediz grubu tortullaşmasının, Çiniliköy formasyonunun 
gölsel çökelleriyle başladığı değerlendirilmiştir. Hakyemez vd. (2013)'te belirtildiği gibi, Gediz Grabeni'nin açılımıyla birlikte $\mathrm{KB}$ yönünde akmış olan eksenel akarsu sistemi (eski Gediz Nehri), Turgutlu'dan itibaren batı ve kuzeybatıya ayrılan yapısal çöküntülerdeki göllere boşalmıştır. $\mathrm{Bu}$ ilişkiye dayanılarak, Gediz havzasının farklı kesimlerinde çökelmiş akarsu ve göl istiflerinin yanal eşdeğer oldukları kabul edilmiştir. Önce Çiniliköy formasyonunun flüviyo-deltaik, daha sonra Kızılca formasyonunun alüviyal ilerlemeleriyle giderek dolan göller, erken Holosen'de açılan Emiralem vadisi üzerinden Ege Denizi'ne boşalmış ve büyük ölçüde kurumuştur.

Kemalpaşa Havzası, Holosen riftleşmesinin başlangıcında işleyen Manisa normal fayı tarafindan Gediz ana havzasindan ayrılmıştır. İkinci evreyi niteleyen Holosen havzası -Gediz havzası genelinde olduğu gibi- birinci evre dolguları üzerinde açılmıştır. Kuzeye içbükey uzanımlı ve yüksek açıyla aynı yöne eğimli verev-normal Kemalpaşa fayı, tek yanlı havza oluşumunu güneyden belirlemiştir. Başlangıcında asimetrik açılan havza, kuzey kıyıda güneye doğru basamaklanan Spil Dağı fay zonunun etkinlikleriyle bağıl simetri kazanmıştır. Akalan çevresinde yüzeyleyen Çiniliköy formasyonu gölsel çökellerinin sistematik olarak güneye çarpılmış olması (Şekil 11a,b), Kemalpaşa fayının Spil Dağı fay zonundan daha etkin olduğunu düşündürür. Buna karşıllk, havzanın batı kesimindeki Kemalpaşa ve Spil Dağı faylarının tavan bloklarında yelpaze sistemlerinin karş1lıklı gelişimlerini sürdürmesi ve Kemalpaşa Çayı'nın eksenel konumu, simetrik gelişimin göstergelerindendir.

Gediz havzası genelinde geç Erken Pliyosen'de başlayan alüviyal, flüviyal ve sınırlı alanlardaki gölsel çökelim, yüksek açılı aktif normal fayların belirlediği Holosen havzalarında günümüzde devam etmektedir.

\section{KATKI BELIRTME}

$\mathrm{Bu}$ çalışmada, "Çeşme, Urla, Cumaovası, Kemalpaşa-Torbalı Çöküntülerindeki NeojenKuvaterner Havzalarının Stratigrafisi ve
Paleocoğrafik Evrimi Projesi” (MTA) kapsamında yürütülen arazi etütlerinin bir bölümü değerlendirilmiştir. Jeoloji Yük. Müh. Murat Yükünç (MTA) ve Jeoloji Yük. Müh. Reyhan Özkan (MTA) arazi çalışmalarına yardımcı olmuşlardır. Makaleyi titizlikle inceleyerek yapıcı önerilerde bulunan Prof. Dr. Nizamettin Kazanc1 (AÜ) ile Prof. Dr. Talip Güngör'e (DEÜ), memeli biyostratigrafisine yönelik değerlendirmelere katkısından dolayı Dr. Serdar Mayda'ya (EÜ), yayınlanmamış küçük memeli tanımlamalarını kullanmamıza izin veren Prof. Dr. Engin Ünay'a ve sondaj loglarından yararlanma olanağı sunan Jeoloji Yük. Müh. Alim Murathan'a (DSI) teşekkür ederiz.

\section{EXTENDED SUMMARY}

The aim of this study is to propose a detailed stratigraphy of the Neogene basement formations and basin fill of late Early Pliocene to Present age of Kemalpaşa basin which forms the western branch of Gediz Graben. Most of studies on tectono-stratigraphic evolution of the Gediz Graben are located on the area between Alaşehir and Turgutlu along its southern margin where the supra-detachment deposition and the multi-phase deformation developed at the last phase of N-S extension are well observed.

Kemalpaşa basin forms the western part of the Gediz Graben. Its basement is composed of Menderes Massif, Cycladic Complex, IzmirAnkaraZone and Bodrum Napperockassemblages, and the Neogene litho-units deposited before late Early Pliocene. These Neogene deposits are Dereköy, Örnekköy and Topçutepe formations, and calcalkaline andesitic Yukarlkızlca volcanics of the Lower-Middle Miocene Kemalpaşa group, and Ulucak formation and Yaka limestone of the Çiçekliköy group deposited in Late Mioceneearly Early Pliocene. All the Neogene and PlioQuaternary units exposed under the Holocene deposits between Gediz Graben Detachment Fault (GGDF) and Spil Dağl were named as the Kuzllca formation in general by Sözbilir et al. (2011). In this study, Örnekköy and Topçutepe formations (Middle Miocene) and Yaka limestone 
(Late Miocene-early Early Pliocene) which they form the Neogene basement of the Kemalpaşa basin, and Çiniliköy and Klzulca formations which represent the basin fill deposited in late Early Pliocene-Pleistocene have been firstly differentiated and mapped in the area mapped as the Kuzllca formation in the paper cited above.

The youngest Neogene deposit of the basement of the Kemalpaşa basin is the Yaka limestone which its upper part can be correlated with the Halitpaşa formation of Kaya et al. (2004) early Early Pliocene in age while the oldest biochronologic data obtained from the Gediz group, which overlies the underlying formations with a regional unconformity, indicate the late Early Pliocene age (late MN15: Mayda et al., 2013). It is suggested that the angular unconformity between the Çiçekliköy group (Late Miocene-early Early Pliocene) and the Gediz group (late Early Pliocene-Present) can be related toa short-term compressional phase described in the previous studies (Koçyiğit et al., 1999; Yılmaz, 2000; Bozkurt, 2000, 2003; Bozkurt and Sözbilir, 2004, 2006; Kaya et al., 2004) and that the Yaka limestone deformed in this process could begin to be eroded by uplifting and affecting from subaerial conditions.

In this paper, it is approved that the Kemalpaşa basin started to open 5 Ma BPby controlling of GGDF and deposition in the Gediz Graben was developed in two main phases, which first one is late Early Pliocene-Pleistocene time and the second is Holocene. This interpretation is compatible with the previous works and the references in those papers which they present data supported the N-S extension prevailed from Miocene up to Present in Western Anatolia has been increased approximately last $5 \mathrm{Ma}$ and the $E-W$ trending grabens were formed in the beginning of this period covered the big amount of total extension (Yllmaz et al., 2000; Bozkurt, 2001a; Taymaz et al., 2001 and references therein).

The first depositional phase in the Kemalpaşa basin represented by Çiniliköy, Kızılca and Armutlu formations, from bottom to top respectively, was developed on the hanging wall of GGDF, which controlled the basin formation asymmetrically along the southern margin. Transgressive overlap of the lacustrine sediments of Ciniliköy formation onto the basement rocks around Akalin village can be an evidence for support the asymmetrical basin formation. The evidences that the first depositional phase was controlled by the GGDF are in the following:

i) The lower part of the Ciniliköy formation is composed of lacustrine sediments and grades up to a deltaic assemblages represented by fluvial conglomerates and cross-bedded sandstones showing a coarsening-upward sequence. ii) Dip angle of the layers in lateral alluvial Kizllca formation increases to the GGDF, and both to GGDF and up to the succession braided river deposits composed of rounded small pebbles gradually change into debris flow deposits with sub angular-sub rounded cobbles and blocks.

As understood from lateral and vertical distribution of the first phase deposits on the hanging wall of the GGDF and their synsedimentary deformation observed from Oren to Kurudere, amount of vertical offset of fault and total thickness of deposits decrease while dip angle of the detachment surface increases. Dip of the fault plane exceeded $30^{\circ}$ in the east of Kurudere gradually goes down to $20-25^{\circ}$ in the area between Ören and Kurudere (Emre et al., 2005), and the outcrops of formations arrange from older to younger in the same direction.

It is interpreted that the deposition of Gediz group in the western (Kemalpaşa district) and northwestern (Manisa-Saruhanl) parts of the Gediz basin began with lacustrine sediments of Ciniliköy formation. As it was remarked in Hakyemez et al. (2013), the axial fluvial system (old Gediz River), which run northwestward along with the opening of the Gediz Graben, discharged into the lakes in structural depressions bifurcated to the west and northwest from Turgutlu. Based on this interpretation, it is accepted that the fluvial and lacustrine successions, which they represent different sedimentation processes in different places of the Gediz basin, are equivalent chronostratigraphically. 
The Holocene basin, which represents the second phase of basin formation, has been opened on the first phase deposits as similar as throughout the Gediz basin. The Kemalpassa fault, which has a northward dipping high-angle oblique normal fault character concave shaped to the North, has controlled the half-graben formation along the southern margin of the basin. The basin opened in an asymmetrical form in the beginning of the basin opening and it gain a relative symmetry because of tectonic activities of the Spil Dağl (Spil Mountain) stepped down southward along the northern margin. Systematically southward inclining of lacustrine deposits of the Çiniliköy formation is suggested that the Kemalpasa fault has been more active than the Spil Dăgl fault zone. Although, continuing the development of lateral fan systems both two sides on the hanging walls of the Kemalpaşa and Spil Dă̆ faults in the west of the basin and axial setting of the Kemalpassa River are indicators of symmetrical development of the Kemalpaşa basin.

Alluvial, fluvial and lacustrine deposition in the Gediz basin, which began in the late Early Pliocene, is still continuing in the Holocene basins controlled by high angle active normal faults.

\section{DEĞIINILEN BELGELER}

Akdeniz, N., Konak, N., Öztürk, Z., Çakır, M.H., 1986. İzmirManisa dolayının jeolojisi. MTA Derleme No: 7929, (yayımlanmamış).

Becker-Platen, J. D., Sickenberg, O., Tobien, H., 1975a. Die Gliederung der Känozoischen sedimente der Türkei nach Vertebraten-Faunengruppen. in: Die Gliederung des höheren Jungtertiärs und Altguartärs in der Türkei nach Vertebraten und ihre Bedeutung für die internationale Neogen-Stratigraphie (Känozoikum und Braunkohlen der Türkei, 17). Geologisches Jahrbuch, B/15, 19-45.

Becker-Platen, J. D., Sickenberg, O., Tobien, H., 1975b. VertebratenLokalfaunen der Türkei und ihre Altersstellung. in: Die Gliederung des höheren Jungtertiärs und Altguartärs in der Türkei nach Vertebraten und ihre Bedeutung für die internationale Neogen-Stratigraphie (Känozoikum und Braunkohlen der Türkei, 17). Geologisches Jahrbuch, B/15, 47-99.

Bozkurt, E., 2001. Neotectonics of Turkey - a synthesis. Geodinamica Acta, 14, 3-30.
Bozkurt, E., 2003. Origin of NE-trending basins in western Turkey. Geodinamica Acta, 16, 61-81.

Bozkurt, E. , Sözbilir, H., 2004. Tectonic evolution of the Gediz Graben: field evidence for an episodic, two-stage extension in western Turkey. Geological Magazine, 141/1, 63-79.

Bozkurt, E. , Sözbilir, H., 2006. Evolution of the large-scale active Manisa Fault, Southwest Turkey: Implications on fault development ve regional tectonics. Geodinamica Acta, 19 (6), 427-453.

Bruijn, H. de, Mayda, S., Ostende, L., Kaya T., Saraç, G., 2006. Small mammals from the Early Miocene of Sabuncubeli (Manisa, SW Anatolia, Turkey). Beitrage zur Paläontologie, 30, 57-87.

Candan, O., Dora, Ö., Oberhanslı, R., Koralay, E., Çetinkaplan, M., Akal, C., Satır, M., Chen, F., Kaya, O., 2011. Menderes Masifi'nin Pan-Afrikan temelin stratigrafisi ve Gondvana'nın Geç Neoproterozoyik/Kambriyen evrimi. Maden Tetkik ve Arama Dergisi, 142, 25-68.

Cohen, H.A., Dart, C.J., Akyüz, H.S., Barka, A.A., 1995. Syn-rift sedimentation and structural development of Gediz and Büyük Menderes graben, western Turkey. Journal of Geological Society, 152, 629-638.

Çiftçi, N.B., Bozkurt, E. 2007. Anomalous stress field and active breaching at relay ramps: a field example from Gediz Graben, SW Turkey. Geological Magazine, 144, 687699.

Çiftçi, N.B., Bozkurt, E. 2008. Folding of the GedizGraben fill, SW Turkey: extensional and/or contractional origin? GeodinamicaActa, 21, 145-167.

Çiftçi, N.B., Bozkurt, E. 2009 a. Pattern of normal faulting in the Gediz Graben, SW Turkey. Tectonophysics, 473, 234260.

Çiftçi, N.B., Bozkurt, E. 2009 b. Evolution of the Miocene sedimentary fill of the Gediz Graben. Journal of Sedimentary Geology,216, 49-79.

Çiftçi, N.B., Bozkurt, E. 2010. Structural evolution of the Gediz Graben, SWTurkey: temporal and spatial variation of the graben basin. Basin Research, 22, 846-873.

Çiftçi, N.B. 2013. In-situ stress field and mechanics of fault reactivation in the Gediz Graben, Western Turkey. Journal of Geodynamics, 65, 136-147. 
Dart, C., Cohen, H.A., Akyüz, H.S., Barka, A.A., 1995. Basinward migration of rift-border faults: Implications for facies distributions and preservation potential. Geology, 23/1, 69-72.

Emre, Ö., Barka, A., 2000. Gediz Grabeni-Ege Denizi arasının (İzmir yöresi) aktif fayları. Batı Anadolu'nun depremselliği Sempozyumu (BADSEM-2000), 24-27 Mayis 2000, İzmir, Bildiriler, 131-132.

Emre, Ö., Özalp, S., Doğan, A., Özaksoy, V., Yıldırım, C., Göktaş, F., 2005. İzmir yakın çevresinin diri fayları ve deprem potansiyelleri. MTA Derleme No: 10754 (yayımlanmamış).

Emre, T., 1996. Gediz grabeninin jeolojisi ve tektoniği. Turkish Journal of Earth Sciences, 5, 171-186.

Ferré, B., 1990. Les mammifères du gisement de Develi (Manisa, Turquie).Mémoire de DEA de Paléontologie, université de Montpellier 2.

Göktaş, F., Ünay, E., 2000. The stratigraphy of the NW parts of the Akhisar (Manisa) Neogene basin. International Earth Sciences Colloquium on the Aegean Region (IESCA-2000), 25-29 September, İzmir, Abstracts, 72.

Göktaş, F., 2012. Kemalpaşa-Torbalı (İzmir) havzası ile yakın çevresindeki Neojen-Kuvaterner tortullaşması ve magmatizmasının jeolojik etüdü. MTA Derleme No: 11575 (yayımlanmamış).

Göktaş, F., 2013. Cumaovası volkanitlerinin zamanstratigrafik konumuna ilişkin yeni veriler hakkında kısa not. Maden Tetkik ve Arama Dergisi, 147, 179-183.

Göktaş, F., 2015. Kemalpaşa-Torbalı (İzmir) havzasındaki Neojen volkanizmasına ilişkin kısa not. Maden Tetkik ve Arama Dergisi, 150 (basıllyor).

Hakyemez, H.Y., Erkal. T., Göktaş, F., 1999. Late Quaternary evolution of the Gediz and Büyük Menderes grabens, Western Anatolia, Turkey. Quaternary Science Reviews, $18,549-554$.

Hakyemez, H.Y., Göktaş, F., Erkal T., 2013. Gediz Grabeninin Kuvaterner Jeolojisi ve Evrimi. Türkiye Jeoloji Bülteni, $56 / 2,1-26$.

ICS (International Commision on Stratigraphy), 2013.. http://www. stratigraphy.org/column.php?id=Chart/Time Scale, 26 February 2013.

İnci, U. 1991., Torbalı (İzmir) kuzeyindeki Miyosen tortul istifinin fasiyes ve çökelme ortamları. Maden Tetkik ve Arama Dergisi, 112, 13-26.
İztan, H., Yazman, M., 1990. Geology and hydrocarbon potential of the Alaşehir (Manisa) area, Western Turkey. International Earth Sciences Colloquium on the Aegean Region (IESCA 1990), 1-6 Ekim 1990, İzmir, Proceedings I, 327-338.

Kaya, O. 1979., Ortadoğu Ege çöküntüsünün (Neojen) stratigrafisi ve tektoniği. Türkiye Jeoloji Kurumu Bülteni, 22/1, 35-58.

Kaya, O., Müller, E.D., Ülkümen, N., Kaya, T., 1998. Biostratigraphic and environmental aspects of the Late Miocene-Early Pliocene deposits in Develiköy (Manisa, Turkey). Mitteilungen der Bayerischen Staatssammlung für Paläontologie und Histor. Geologie, 38, 3-7.

Kaya, O., Ünay, E., Saraç, G., Eichhorn, S., Hassenrück, S., Knappe, A., Pekdeğer, A., Mayda, S., 2004. Halitpaşa Transpressive Zone: Implications for an Early Pliocene compressional phase in central Western Anatolia, Turkey. Turkish Journal of Earth Sciences, 13, 2-13.

Kaya, O., Ünay, E., Göktaş, F., Saraç, G., 2007. Early Miocene stratigraphy of Central West Anatolia, Turkey: implications for the tectonic evolution of the Eastern Aegean area. Geological Journal, 42, 85-109.

Kaya, T., 1994. Ceratoterium neumayri (Rhinocerotidae-Mammalia) in the Upper Miocene of Western Anatolia. Turkish Journal of Earth Sciences, 3/1, 13-22.

Koçyiğit, A., Yusufoğlu, H., Bozkurt, E., 1999. Evidence from the Gediz graben for episodic two-stage extension in Western Turkey. Journal of the Geological Society, 156, 605-616.

Konak, N., Çakmakoğlu, A., 2007. Menderes Masifi ve yakın çevresindeki Mesozoyik-Alt Tersiyer istiflerinin tektonik üniteler bazında tartışılması. Menderes Masifi Kolokyumu, 5-10 Kasım 2007, İzmir, Genişletilmiş Bildiri Özleri Kitabı, 56-64.

Mayda, S., 2008. Sabuncubeli (Manisa) Erken Miyosen memeli faunasının sistematiği ve biyostratigrafisi. Doktora Tezi, Ege Üniversitesi Fen Bilimleri Enstitüsü, 224 s.

Mayda, S., Titov, V.V., Tesakov, A.S., Göktaş, F. ve Alçiçek, M.C., 2013. Revision of Plio-Pleistocene mammalian faunas from Çobanisa area (Western Turkey). VIII All-Russian Conference on Quternary Research, "Fundamental Problems of Quaternary, Results and Main Trends of Future Studies, 10-15 June 2013, Rostov-on-Don, Collection of papers, 396-397.

Mayda, S., 2014, Kişisel görüşme. Ege Üniversitesi Tabiat Tarihi Müzesi, İzmir. 
Okay, A., Siyako, M., 1991. The new position of the İzmir-Ankara Neo-Tethyan Suture between İzmir and Balıkesir. Ozan Sungurlu Symposium, 26-28 Kasım 1991, Ankara, Proceedings, 333-355.

Özkaymak, Ç., Sözbilir, H., 2008. Stratigraphic and Structural Evidence for Fault Reactivation: The Active Manisa Fault Zone, Western Anatolia. Turkish Journal of Earth Science, 17, 615-635.

Özkaymak, Ç., Sözbilir, H., Uzel, B., 2012. Neogene-Quaternary evolution of the Manisa Basin: Evidence for variation in the stress pattern of the Izmir-Balıkesir Transfer Zone, western Anatolia. Journal of Geodynamics, 65, 117-135.

Paton, S., 1992. Active normal faulting, drainage patterns and sedimentation in southwestern Turkey. Journal of the Geological Society, 149, 1031-1044.

Purvis, M., Robertson, A., 2004. A pulsed extension model for the Neogene-Recent E-W trending Alaşehir Graben and the NE-SW trending Selendi and Gördes Basins, western Turkey. Techtonophysics, 391, 171-201.

Purvis, M., Robertson, A., 2005. Sedimentation of the NeogeneRecent Alaşehir (Gediz) continental graben system used to test alternative tectonic models for western (Aegean) Turkey. Sedimentary Geology, 173, 373-408.

Rummel, M., 1998. Die Cricetiden aus dem Mittel- und Obermiozän der Türkei. Documenta Naturae, 1-300, München.

Saraç, G., 2003. Türkiye omurgalı fosil yatakları. MTA Derleme No: 10609 (yayımlanmamış).

Sarıca, N., 2000. The Plio-Pleistocene age of Büyük Menderes and Gediz grabens and their significance on N-S extensional tectonics in West Anatolia: mammalian evidence from the continental deposits. Geological Journal, 35, 1-24.

Seyitoğlu, G., Scott, B., 1996. Age of the Alaşehir graben (West Turkey) and its tectonic implications. Geological Journal, 31, 1-11.

Seyitoğlu, G., Çemen, İ., Tekeli, O. 2000. Extensional folding in Alaşehir (Gediz) graben. Journal of the Geological Society London, 157, 1097-1100.

Seyitoğlu, G., Tekeli, O., Çemen, İ., Şen, Ş., Işık, V., 2002. The role of the flexural rotation/Rolling hinge model in the tectonic evolution of the Alaşehir graben, western Turkey. Geological Magazine, 139/1, 15-26.

Sözbilir, H., 2001.Extensional tectonics and the geometry of related macroscopic structures: field evidence from the Gediz detachment, Western Turkey. Turkish Journal of Earth Sciences, 10, 51-67.

Sözbilir, H., Sarı, B., Uzel, B., Sümer, Ö., Akkiraz, S., 2011. Tectonic implications of transtensional supradetachment basin development in an extension-parallel transfer zone: the Kocaçay Basin, western Anatolia,Turkey. Basin Research, 23, 423-448.

Steininger, F.F., 1999. Chronostratigraphy, geochronology and biochronology of the Miocene "European Land Mammal Mega-Zones" (ELMMZ) and the Miocene "MammalZones (MN-Zones)". Rössner, G. and Heissig, K. (eds). The Miocene Land Mammals of Europe, München, Verlag Dr. Friedrich Pfeil, 9-24.

Şahinci, A., 1976. Manisa yöresi Gediz alüvyonları hakkında bazı incelemeler. Ege Üniversitesi Fen Fakültesi İlmî Raporlar Serisi, 233, İzmir, $11 \mathrm{~s}$.

Şen, Ş., Jaeger, J.J., Dalfes, N., Mazin, J.M., Bocherens, H., 1989. Decouverte d'une faune de petits mammiferes pliocenesen Anatolie occidentale. Comptes rendus de 1)Académie des Sciences, 309, 1729-1734.

Şen, Ş., Seyitoğlu, G. 2009. Magnetostratigraphy of early-middle Miocene deposits from east-west trending Alaşehir and Büyük Menderes grabens in western Turkey, and its tectonic implications. In: Van Hinsbergen, D. J. J., Edwards, M. A. \& Govers, R. (eds) Collision and Collapse at the Africa-Arabia-Eurasia Subduction Zone. The Geological Society, London,Special Publications, 311, $321-342$.

Taymaz, T., Demirbağ, E., Genç, T., Kurt, H., Tan, O., Ocakoğlu N., 2001. Ege Denizi ve çevresindeki yıkıcı depremler ile graben yapıları ve kıta şelfinin sismik özelliklerinin incelenmesi. TÜBİTAK Nihai Rapor, Proje No: YDABÇAG-198Y075.

Ünay, E., Göktaş, F., Hakyemez, H.Y., Avşar, M., Şan, Ö. 1995. Büyük Menderes Grabeni'nin kuzey kenarındaki çökellerin Arvicolidae (Rodentia, Mammalia) faunasına dayalı olarak yaşlandırılması. Türkiye Jeoloji Bülteni, $38 / 2,75-80$.

Ünay, E., 1997. Kişisel görüşme. Maden Tetkik ve Arama Genel Müdürlüğü, Ankara.

Ünay, E., De Bruijn, H., 1998. Plio-Pleistocene rodents and lagomorphs from Anatolia. Mededelingen Nederlands Instituut voor Toegepaste Geowetenschappen TNO, 60, $431-465$. 
Ünay, E., Göktaş, F., 1999. Söke çevresi (Aydın) geç Erken Miyosen ve Kuvaterner yaşlı küçük memelileri: ön sonuçlar. Türkiye Jeoloji Bülteni, 42/2, 99-113.

Ünay, E., De Bruijn, H, Saraç, G., 2003. A preliminary zonation of the continental Neogene of Anatolia based on rodents. In: Reumer, J.W.F. \& Wessels, W. (eds.). Distribution and migration of Neogene mammals in Eurasia. Deinsea, 10, 530-547.

Yalçınlar, İ., 1953/54. Manisa bölgesinin omurgalı Neojen faunası yatakları ve aşağı Gediz vadisinin menşei hakkında. İstanbul Üniversitesi Coğrafya Enstitüsü Dergisi, 5/6, 197-204.

Yılmaz, Y., 2000. Ege bölgesinin aktif tektoniği. Batı Anadolu'nun depremselliği Sempozyumu (BADSEM-2000), 24-27 Mayıs 2000, İzmir, Bildiriler, 3-14.
Yılmaz, Y., Genç, Ş. C., Gürer, F., Bozcu, M., Yılmaz, K., Karacık, Z., Altunkaynak, Ş., Elmas, A., 2000. When did the western Anatolian grabens begin to develop?, In: Bozkurt, E., Winchester, J.A. ve Piper, J.A.D. (eds). Tectonic and Magmatism in Turkey and the Surrounding Area. Geological Society, London, Special Publications, 173, 353-384.

$\begin{array}{ll}\text { Makale Geliş Tarihi } & : \text { 04 Aralık } 2014 \\ \text { Kabul Tarihi } & : \text { 13 Ocak } 2015 \\ & : \text { 04 December } 2014 \\ \text { Received } & : \text { 13 January 2015 }\end{array}$

